Stoa

Vol. 12, no. 23, 2021, pp. 100-146

ISSN 2007-1868

\title{
ANTONIO ROSMINI: UNA NUEVA METAFÍSICA DEL SER*
}

\author{
A new metaphysics of being
}

\author{
Battista Mondin
}

RESUMEN: Presentamos la traducción del capítulo correspondiente a la metafísica de Antonio Rosmini que se halla en la imponente obra de Battista Mondin Storia della metafisica. Esta obra presenta el pensamiento metafísico de los más insignes filósofos occidentales, desde los orígenes hasta nuestros días. Es una obra que abarca, en sus tres volúmenes, unas tres mil cuartillas, y su traducción es objeto de este traductor. Como adelanto, presentamos el capítulo que elabora el filósofo véneto sobre el filósofo roveretano. Como el resto de los capítulos de su obra, el correspondiente a Rosmini posee las características de la claridad expositiva y la precisión en el uso de los conceptos. Para todo aquel interesado en la metafísica en general, y especialmente en la metafísica cristiana, este documento ha de resultar de sumo interés.

PALABRAS CLAVE: Metafísica $\cdot$ platonismo $\cdot$ aristotelismo $\cdot$ tomismo $\cdot$ ser $\cdot$ posibilidad.

ABSTRACT: I present the translation of the chapter corresponding to Antonio Rosmini metaphysics' that is founded in the important work of Battista Mondin: Storia della metafisica. This book presents the metaphysical thought of the most distinguished Western philosophers, from the origins to the present day. It is a work that covers, in its three volumes, about three thousand pages, and I am translating it to spanish. As a preview, I present the chapter that the Venetian philosopher elaborates on the Roveretan philosopher. Like the rest of the chapters of his work, the one corresponding to Rosmini has the characteristics of expositional clarity and precision in the use of

\footnotetext{
* Traducción de Jacob Buganza.
}

Recibido 8 de septiembre Aceptado 12 de octubre 
concepts. For anyone interested in metaphysics in general, and especially in Christian metaphysics, this document should be of great interest.

KEYWORDS: Metaphysics · platonism · aristotelism · thomism · being · possibility.

\section{Introducción}

En el siglo XIX, que es un siglo decididamente antimetafísico, la "reina de todo saber" encuentra todavía algún válido defensor, especialmente en el mundo católico, pero se trata casi siempre de abogados de la vieja metafísica escolástica, tal como había sido reciclada por Suárez. De este cuadro más bien opaco, emerge la figura prestigiosa de Antonio Rosmini, un pensador católico que poseía las cualidades del auténtico metafísico. El objetivo principal de todo su trabajo filosófico fue el de construir una nueva metafísica que estuviese en grado de afrontar y responder a todos los desafíos del pensamiento moderno, tanto los de Descartes y Spinoza, como los de Hume, Kant y Hegel. Rosmini es el único gran metafísico del ochocientos y merece, por tanto, un tratamiento adecuado. Es cuanto buscaremos hacer en el presente capítulo.

\section{Vida}

Antonio Rosmini nació en Rovereto el 24 de marzo de 1797 en el seno de una familia patricia. Efectuó sus estudios elementales, medios y medio superiores en la ciudad natal, manifestando desde joven una inteligencia de tipo enciclopédico, que progresivamente se afina y madura, en el curso de los años, pasando del corte meramente clasificatorio (es de este periodo el empeñativo proyecto de publicar una edición revisada y corregida del Vocabulario de la Crusca) de los proyectos juveniles, a una concepción orgánico-sistemática del saber, teorizada completamente en el periodo de la madurez.

En 1816, terminados los estudios de liceo, deja Rovereto para entrar en la Universidad de Padua donde, en 1822, se licencia en teología y derecho canónico. En Padua la enseñanza de la teología dogmática estaba a cargo del dominico Tommasoni, "hombre doctísimo y de piedad singular", de orientación tomista, pero que, en su enseñanza, se había adecuado al nuevo sistema de estudios impuesto por Austria, en el que se daba amplia prevalencia a la historia eclesiástica, con particular atención a la patrología y a la historia literaria teológica, a la lengua hebrea y a la arqueología hebrea, a la exégesis bíblica y al derecho canónico público y privado. La teología dogmática resultaba así institucionalmente desclasada, pero se ofrecía también la posibilidad 
de una mayor justificación documentaria para aquella corriente de teología apologética y polémica, de defensa e ilustración del dogma, que Tommasoni, perfectamente en línea con la dirección de la escolástica post-tridentina y contrarreformada, estaba elaborando. "Conseguida la licencia en teología, Rosmini continuó viendo en la cultura la necesidad y en el horizonte de la fe una atmósfera de decisiva y profunda ascesis" (G. Di Napoli).

El joven Rosmini era ya una persona muy pía y profundamente creyente. En su Diario personal, en 1813 anotaba: "Este año fue para mí un año de gracia: Dios me abrió los ojos sobre muchas cosas y conocí que no hay otra verdadera sabiduría más que en Dios". Y creyente profundo y ascético permaneció Rosmini durante toda su vida. Dedicado a la constante purificación de sí, deseoso de vivir en la santidad, dedicó todo a la "salvación del alma". Sus Máximas de perfección cristiana representaban el paradigma sintético y denso de una vida absorbida por un teocentrismo radical, fundada sobre eminentes principios de humildad (principio de pasividad), en el abandono incondicionado a Dios, en el cual sólo está la sabiduría verdadera que hay que amar y buscar. La vida de Rosmini fue una experiencia teológica: es el "Rosmini asceta y místico" del que habla C. Rebora (Rosmini asceta e mistico, Venecia 1980).

En 1827 es ordenado sacerdote. Se transfirió a Milán (donde entabló una profunda y duradera amistad con Manzoni) y sucesivamente a Domodossola, donde fundó una congregación religiosa (el Instituto de la Caridad), cuyos adeptos, luego de su muerte, asumieron el nombre de rosminianos. En 1848 Carlos Alberto lo mandó en misión diplomática a Roma para inducir a Pío IX a participar en la guerra contra Austria. Por varias complicaciones, la misión fracasó y, lo que es peor, dos obras en las que Rosmini propugnaba la renovación de la Iglesia, la Constitución y Las cinco llagas, fueron enviadas al Índice, porque se consideraban inoportunas. Como consecuencia de esto, Rosmini, caído en desgracia tanto para el Papa como para el Rey, se retiró a Stresa donde, abandonando la política, se dedicó exclusivamente a la filosofía y la teología. Ahí murió el 1 de julio de 1855.

La hostilidad hacia Rosmini no se aplacó ni siquiera después de su muerte. Mientras un examen de sus obras se había concluido en 1854 sin ninguna condena eclesiástica, en 1880 el decreto Post obitum condenó 40 proposiciones extraídas de sus obras, especialmente póstumas. Propiamente el decreto condena cuarenta proposiciones extraídas no sólo de las obras publicadas póstumamente, sino también de las ya examinadas y sometidas, colocando el 
problema históricamente relevante de la eventual contradicción o de la deseable conciliación con el Dimittantur de 30 años antes. Las condena simplemente, sin poner después alguna nota teológica, estimulando la necesidad de entender el sentido y la fuente doctrinal de este hecho. En fin, la condena en proprio auctoris sensu, inmunizándose de un eventual vaciamiento suyo por la objeción de quien no querría advertir y ver en las proposiciones condenadas el sentido auténtico de Rosmini, sino sólo un sentido tergiversado.

La razón última de la condena no se busca tanto en la presencia en el pensamiento de Rosmini de alguna herejía particular y específica, sino por la línea innovadora de pensamiento que, en una época de profunda unidad y uniformidad del pensamiento católico, era considerada inaceptable. "La idea de que en el ámbito del catolicismo fuera posible un pluralismo filosófico (y teológico) no era aceptada por los neotomistas (en ese entonces muy influyentes): de aquí su agresividad hacia el pensamiento rosminiano, que no era sólo discutido racionalmente, sino acusado de heterodoxia" (S. Vanni Rovighi).

\section{Obras}

Rosmini fue un escritor fecundísimo. Sus obras se pueden repartir en tres secciones: filosóficas, teológicas y ascéticas. Muchos escritos aparecieron póstumos. He aquí el elenco de las obras principales.

A) Escritos filosóficos

Nuovo saggio sull'origine delle idee (1830), Principi della scienza morale (1831), Storia comparativa e critica dei sistemi intorno al principio della morale (1838), Trattato della coscienza morale (1839), Filosofia del Diritto (1845), Psicologia (1850), Teosofia (post.): esta última es la expresión más completa del sistema metafísico de Rosmini (comprende ocho volúmenes), iniciada en 1846 pero ha quedado incompleta.

\section{B) Escritos teológicos}

Il lenguaggio teologico, Antropologia soprannaturale, Introduzione al Vangelio secondo Giovanni (los tres publicados póstumos), Della divina providenza nel governo dei beni temporali (1826), Teodicea (1845).

C) Escritos ascéticos

Ascetica (1840), Massime di perfezione cristiana adattate ad ogni condizione di persone (1830), Delle cinque piaghe della santa Chiesa (1848). 
Para completar el cuadro de los escritos de Rosmini, hay que tener en cuenta el vastísimo epistolario en 13 volúmenes: Epistolario completo (18871894).

\section{Los objetivos de Rosmini}

El objetivo primario de todo el trabajo intelectual de Rosmini tiende a la renovación profunda de la filosofía, de la teología y, en general, de la cultura católica que, luego de la revolución francesa, estaba atravesando una serie crisis, profunda y alarmante, abrumada y a veces seducida por el racionalismo y el iluminismo. Para conseguir este objetivo, Rosmini retoma y hace suya la idea, que ya había sido dada por Agustín y Tomás, de presentar la "enciclopedia cristiana" de todo el saber y contraponerla a la enciclopedia laica de los iluministas franceses, buscando al mismo tiempo un dificilísimo diálogo con el pensamiento post-cartesiano, intrínsecamente inmanentista.

El inmanentismo moderno sacaba el principio unificador de todo el saber de la subjetividad, que podía ser el Yo trascendental de Fichte, el Espíritu de Hegel, la Voluntad de Schopenhauer, la Clase de Marx. Pero la subjetividad es (por sí) incapaz de sostener la carga de una unificación del saber, porque la subjetividad aplaza por sí al objeto que la regula y vuelve posible. A este objeto —entendido naturalmente en su acepción más amplia y universal, es decir, como dimensión metafísica - recurre, pues, Rosmini para recrear las condiciones filosóficas de una enciclopedia que garantice y no comprometa la coherencia del pensar; y esto explica el papel fundamental que viene a asumir en el sistema rosminiano la noción de "ser ideal", que se relaciona explícitamente a la noción tomasiana de esse commune rerum. ${ }^{1}$

En el siglo XIX ningún otro estudioso advirtió la instancia de una renovación substancial de la cultura católica como Rosmini. Toma en serio el movimiento ideal europeo conocido bajo el nombre de "siglo de las luces". Tal cultura iluminada se jactaba de haber puesto fin al mito cristiano y de haber acantonado una tradición considerada muerta para siempre. Rosmini se esfuerza por interrogar a esta filosofía, por penetrar en sus profundas exigencias, por estudiar la problemática para proponer una nueva formulación filosófica capaz de presentar la verdad del pasado como respuesta contemporánea. Rosmini entendió la urgencia de una profunda renovación del pensamiento católico en el ámbito filosófico y teológico, y proyectó una especial enciclopedia

\footnotetext{
${ }^{1}$ R. Besserti Belti 1984, pp. 101-108.
} 
de inspiración cristiana para responder a la de Diderot y d'Alembert y de los demás iluministas franceses.

Substancialmente son estos los objetivos prefijados por Rosmini mismo en su Introduzione alla filosofia, donde enuncia cuatro fines para los estudios personales: 1. Combatir los errores, 2. Reducir la verdad a sistema, 3. Elaborar una filosofía que pueda ser sólida base para la ciencia, 4. Y de la que pueda valerse la teología. Buscaba, como escribe en el Linguaggio teologico, responder a la apremiante e ininterrumpida necesidad de la Iglesia de una sana filosofía que sirviese tanto al objetivo "de rebatir las objeciones de los no creyentes, como también, por el otro, no menos importante, de ordenar, penetrar en la inteligencia de la verdad revelada".

Así, el empeño constante de Rosmini en filosofía, teología, pastoral, liturgia fue "modernizar", en los límites de lo posible, la gran tradición católica, teniendo en cuenta las nuevas instancias culturales, sociales y políticas que habían emergido en el mundo contemporáneo luego de la experiencia del racionalismo, del iluminismo, del criticismo y de la Revolución francesa. Algunas soluciones propuestas por Rosmini sobre el terreno litúrgico y pastoral no fueron comprendidas por prematuras; otras de orden especulativo fueron contrariadas en cuanto intrínsecamente discutibles; sin embargo, su obra, en su conjunto, constituye una de las tentativas más lúcidas y valientes por realizar, con la renovación de la filosofía y la teología, un encuentro entre cristianismo y mundo moderno.

En el campo filosófico, el objetivo principal de Rosmini es relanzar la metafísica, cuyas bases habían sido sacudidas por el empirismo humeano y el criticismo kantiano, proponiendo una nueva doctrina del conocimiento, la cual tiene como objeto primario, es más único, al ser. Contra Hume y Kant, que habían afirmado que el ser en cuanto tal es vano, Rosmimi reafirma la clásica tesis de Aristóteles, Avicena, Tomás, Escoto según la cual el primer objeto de la mente es el ser.

Por tanto, la metafísica de Rosmini es esencialmente una metafísica del ser, la cual, sin embargo, se distingue de las grandes metafísicas del ser de Aristóteles y Tomás no tanto en los contenidos sino en el método: diversamente de Aristóteles y Tomás, quienes utilizaban el método inductivo-resolutivo, Rosmini recurre al método sintético (sintesismo es el nombre que Rosmini da a su sistema). El encuentro con la realidad es obra del intelecto, como en

${ }^{2}$ Sistema filosofico. 
Aristóteles y Tomás; pero para Rosmini tal encuentro no es concebido como una indagación y una resolutio de lo real -el ente finito, contingente, participado - de parte del intelecto, sino como una síntesis entre el ser ideal y el ser real. De aquí la importancia capital que tiene el capítulo de la gnoseología (ideología) en el sistema rosminiano. En efecto, todo este sistema se tiene en pie en la medida en que se tiene en pie su teoría en torno al ser ideal.

A la renovación de la ideología le sigue la renovación de las otras partes de la metafísica: la antropología y la teología natural.

\section{El prólogo gnoseológico: el ser ideal}

Sabemos ya que la metafísica clásica ponía gran atención al problema gnoseológico y lo afrontaba como prólogo a la investigación metafísica, para ponerla al abrigo de cualquier sorpresa. De hecho, un sabio marinero, antes de lanzarse en una difícil y complicada travesía, tiene el cuidado de verificar las condiciones de la propia barca; busca ver que todo esté en orden: los remos, la quilla, las velas, etcétera. El metafísico, antes de iniciar la segunda navegación, debe hacer lo mismo: debe verificar la bondad de su nave - que es la razón - y someter a severo examen los equipos de los que dispone. Es cuanto hicieron Platón y Aristóteles en la Antigüedad, Agustín y Tomás en el Medioevo, Descartes y Kant en la época moderna.

Rosmimi, antes de embarcarse con su nave y lanzarse a la empresa de la segunda navegación, hace lo mismo. Rosmini construye todo su imponente edificio filosófico sobre el ser, en el cual distingue tres formas o manifestaciones principales: la forma ideal, la forma real y la forma moral. ${ }^{3}$ De la forma ideal se ocupa en la ideología (gnoseología), de la forma real en la metafísica y de la forma moral en la ética.

Por tanto, en el sistema rosminiano la gnoseología es mucho más que un simple prólogo a la metafísica, como podría ser en Aristóteles o en Descartes, porque aquello de lo que se ocupa Rosmini en esta parte de la filosofía no es tanto de la bondad de los procesos cognoscitivos (la razón y los sentidos), sino también la cualidad y naturaleza de su objeto, que en definitiva es siempre el ser. Esto da una valencia ontológica, además de lógica, a toda la doctrina rosminiana del conocimiento.

${ }^{3}$ Cf. Il sistema filosofico, nn. 178-182. 
La ideología de Rosmini se apoya sobre tres tesis fundamentales: 1) la intuición del ser ideal, 2) la síntesis del ser real y 3) los conceptos de substancia y causa. Veámoslas una por una.

\section{La intuición del ser ideal}

Para Rosmini, la del ser es la "madre de todas las ideas"; ella es, por ende, la primogénita de todas las ideas, la primera idea que se asoma a nuestra inteligencia.

Que la idea de ser (ente) goza de un primado respecto a todas las otras ideas, era tesis comúnmente admitida por la metafísica clásica y medieval. Avicena al inicio de su Metafísica había escrito que "el ente es el primer universal que comprende toda cosa en su intelección universal" (ens est primum universale aggregans omnia in sua intentione universali). Estas célebres afirmaciones del filósofo árabe fueron retomadas y compartidas por todos los medievales.

Rosmini regresa a esta tesis clásica, pero la vuelve a proponer en un nuevo contexto que es el de Kant, el cual, como sabemos, para dar valor absoluto al conocimiento intelectivo, la dotaba de un cierto número de conceptos fundamentales, a priori, las categorías, a las cuales, sin embargo, asignaba un valor subjetivo y no objetivo.

Rosmini está de acuerdo en la necesidad de que en el conocimiento hay un elemento a priori, que, sin embargo, él reduce a la sola idea de ser; pero contra Kant afirma la absoluta objetividad de este elemento a priori.

En la Introducción a la Antropologia in servizio della scienza morale Rosmini resume felizmente sus "postulados" en torno a su concepto de ser, que asumen connotaciones muy distintas a las categorías kantianas. He aquí sus tesis fundamentales:

El ser es lo que se conoce primero. Cualquier otro conocimiento siempre presupone que se conoce el ser [...] pues todo objeto de nuestro pensamiento es una entidad, un ser posible o real [...] Si entonces el ser es conocido por sí mismo, no puede esperarse una definición de él, pero es necesario que se conceda su noticia dada de manera anterior a cualquier otro razonamiento. Por lo tanto, nuestro postulado queda justificado. ${ }^{4}$

Todo el sistema de lo cognoscible humano presupone al ser como algo conocido; por tanto, el ser contiene propia y naturalmente la luz de la mente, o sea, de la idea. $^{5}$

${ }^{4}$ Antropologia in servizio della scienza morale, n. 10.

5 Ibid., n. 12. 
El ser como luz de la mente es llamada propiamente ser ideal, o simplemente idea. También la llamamos idea de ser o ser posible. Estas denominaciones implican sin embargo alguna relación mental, más allá del puro ser ideal. ${ }^{6}$

Si el ser es en sí mismo luz o idea, constituye la esencia o forma del conocer. Por tanto, es el lugar de la evidencia a la que, en orden a ser perfecta, todas las demostraciones de las ciencias deben conducir como a su término final para que sean perfectas. ${ }^{7}$

todas las potencias intelectivas, toda la actividad del hombre en cuanto es un ser dotado de inteligencia, tiene su fuente en aquel acto primero con el cual el espíritu humano intuye al ser, y así, junto al ser, y suscitado por el ser, concurre a producir la propia inteligencia. ${ }^{8}$

En precedencia, en los Principi della scienza morale, Rosmini había explicado con toda claridad qué cosa es el ser ideal del modo siguiente:

En el ser humano hay una idea que precede a todas las otras y con la cual se forman todos los juicios [...] Esta idea con la cual la mente humana forma juicios es la idea del ente en universal, idea congénita en el espíritu humano y forma de la inteligencia. La llamo la forma de la inteligencia porque un análisis de los pensamientos humanos nos los muestra informados de cierta manera que el pensamiento es inconcebible sin ella. Sin ella, cualquier espíritu estaría desprovisto de su inteligencia [... E En verdad conviene observar que todas las cosas y sus partes, igual que sus perfecciones, son, en último término, actos del ser. El ser, actualizado y limitado en diferentes sentidos, recibe diversos nombres en distintas cosas. La palabra ser significa simplemente la primera actividad y toda actividad. ${ }^{9}$

El ser ideal es considerado en sí mismo y en relación a la mente, porque "la naturaleza del ser ideal es tal que, uniendo en sí misma, sin alguna contradicción, dos modos de existencia, uno en sí y otro relativo a la mente, o para decirlo mejor, teniendo un modo de existencia que abraza a estos dos, vuelve posible la comunicación de sí a una mente”. El ser en relación a la mente es el ser intuido y en ello "yacen escondidos todos sus términos, unido a los cuales presenta al pensamiento los conceptos de los entes". ${ }^{10}$ Decir que el ser es intuido, es decir, que está presente a nuestro espíritu y lo comprendemos con un "sentido intelectual sui generis", no tiene sólo el valor funcional de forma del

\footnotetext{
${ }^{6}$ Ibid., nota al n. 12 .

${ }^{7}$ Ibid., n. 13.

${ }^{8}$ Ibid., n. 508.

${ }^{9}$ Principi della scienzia morale I, 2.

${ }^{10}$ Teosofia I, n. 213.
} 
conocimiento. Su naturaleza es forma objetiva, y por ende "sucede que tiene las dos relaciones de las que hemos hablado (forma de la cognición y al mismo tiempo de la potencia para conocer), esto es, que ella es al mismo tiempo manifestante y manifestada. Bajo la relación de manifestante se llama forma de la mente, porque sin ella la mente no sería mente, la facultad para conocer no sería cognoscitiva. Bajo la relación de manifestada se llama forma de la cognición, porque constituye el objeto conocido, lo que se tiene de objetivo y por ello de formal en toda cognición". ${ }^{11}$

Pero, ¿cómo es apresada la idea del ser por nuestra mente? En los pasajes citados hasta ahora hemos encontrado varias veces las expresiones "intuición", "intuido". Y esta es precisamente la tesis que Rosmini sostiene vigorosamente contra aquellos que confirman que la idea del ser es fruto de la abstracción o bien que el ser es apresado sólo en el juicio.

En el Nuovo saggio sull'origine delle idee, Rosmini dedica un amplio capítulo a la cuestión sobre el "origen de la idea del ser", donde hace ver que ella no puede ser el resultado de un juicio, en cuanto todo juicio la presupone, y ni siquiera de la abstracción. Indudablemente la abstracción es una operación con la que nos formamos muchas ideas, pero no la del ser. En efecto, "si luego de haber eliminado de un ente todas las otras cualidades, tanto las propias como las comunes, quitad todavía la más universal de todas, el ser; ya no os queda nada en vuestra mente, todo vuestro pensamiento desaparece, es imposible que tengáis idea alguna de aquel ente". ${ }^{12}$

Con la abstracción se descubre que en toda idea la del ser está contenida, pero la idea del ser no es un producto de la abstracción, sino que le es anterior. Efectivamente, "la idea del ser es tan necesaria que entra esencialmente en la formación de todas nuestras ideas, de suerte que no tenemos la facultad para pensar sino mediante su uso". ${ }^{13}$ Por tanto, la idea de ser no es parida por nuestra mente. De aquí la conclusión de Rosmini: "queda que la idea del ser sea innata en nuestra alma; así que nosotros conocemos con la presencia y visión del ser posible (idea del ser), si bien no nos damos cuenta hasta mucho más tarde". ${ }^{14}$

La idea del ser que se encuentra desde siempre presente en nuestro espíritu es apresada intuitivamente: "el espíritu humano intuye por naturaleza el ser

\footnotetext{
${ }^{11}$ Ibid. IV. p, 461.

${ }^{12}$ Nuovo saggio, II, n. 412.

${ }^{13}$ Ibid., n. 468.

${ }^{14}$ Ibid.
} 
ideal" ${ }^{15}$ Cualquier conocimiento ulterior, cualquier pensamiento, según Rosmini, no es otra cosa que una determinación y una "explicitación" de la idea del ser.

El espíritu humano intuye por naturaleza al ser ideal indeterminado. Esta no es potencia sino acto. Es un acto esencial para el espíritu, es el intelecto en cuanto entra a constituir un elemento de la naturaleza humana. Pero si el ser ideal, presente naturalmente en el espíritu humano adquiere alguna relación con el mundo real mediante las sensaciones, entonces el intelecto intuye al ser ideal dotado de alguna determinación, y para este nuevo acto intelectivo está en potencia. Esta es la que se llama potencia del intelecto. ${ }^{16}$

\section{La síntesis primitiva (del ser con la realidad del juicio)}

Según Rosmini, de la intuición nativa del ser proceden todos los otros conocimientos mediante un proceso de síntesis. La "síntesis primitiva" es la que realiza el intelecto mediante la aplicación de la idea del ser a los datos de la sensación. Tal aplicación tiene lugar en el juicio. Sobre este punto Rosmini se acerca a Kant, el cual, como sabemos, concebía todos los juicios como síntesis, y los juicios sintéticos a posteriori como síntesis entre las categorías del intelecto y los datos de lo sentido. Por su parte, Rosmini afirma que "la idea del ente en general es la idea con la cual la mente forma todos los juicios"; mientras que la síntesis primitiva tiene lugar cuando "el ser ideal, presente naturalmente en el espíritu humano, adquiere alguna relación con el mundo mediante las sensaciones". ${ }^{17}$

Sobre las hormas de Kant, Rosmini caracteriza al elemento dotado del intelecto como forma y el dotado por la sensación como materia. La síntesis de una y la otra es la percepción intelectiva o juicio primitivo, "mediante el cual el espíritu afirma que existe alguna cosa percibida por los sentidos". La síntesis de materia y forma es el conocimiento efectivo y objetivo de las cosas; en efecto, la percepción intelectiva, como "percepción", apresa sensiblemente al ente que está fuera y, como "intelectiva", como determinación del ser ideal, como idea del ente particular. Percibir un ente intelectualmente significa pronuncia un juicio existencial, "esta cosa es".

\footnotetext{
${ }^{15}$ Antropologia in servizio della scienzia morale, n. 510.

${ }^{16}$ Ibid.

${ }^{17}$ Ibid.
} 
Según Rosmini, el conocimiento de las cosas sucede de la siguiente manera. Tenemos antes que nada un "sentimiento fundamental" con el que percibimos mediante nuestro cuerpo "como una cosa con nosotros"; y luego, a través del cuerpo, recibimos la impresión de las cosas distintas de nosotros. Cuando aplicamos la idea del ser al sentimiento fundamental, obtenemos la idea de nosotros mismos, la autoconciencia; cuando aplicamos la idea del ser a las impresiones distintas a nosotros, adquirimos la hetero-conciencia.

\section{La razón}

El juicio no genera nuevas ideas, sino que da un cuerpo, una materia a la idea del ser, y forma así conceptos de las cosas particulares, que pueden ser tanto conceptos generales como particulares: "con la percepción intelectiva el hombre aprehende los seres reales". ${ }^{18}$, n. 512.

En cambio, la razón tiene la función de procurar nuevas ideas: "la razón aplica este ser ideal e indeterminado para ilustrar y volver cognoscibles las cosas que no son conocidas al hombre por sí mismas". ${ }^{19}$ A esta categoría de cosas no inmediatamente cognoscibles pertenecen obviamente todas las realidades inmateriales y espirituales y, en modo especial, Dios. Escribe Rosmini en un pasaje significativo de la Antropologia:

Adquiridas de tal manera las percepciones de los entes reales, la razón puede hacerles nuevas aplicaciones del ser ideal. Con una de estas aplicaciones puede pasar de su contingencia y limitación a reconocer la existencia de un primer ser necesario e ilimitado. Esta es una segunda función de la razón, la integración, la cual se efectúa mediante el principio de absolutidad. Con un uso así de noble de la razón, el hombre deviene en posesión de una nueva riqueza intelectiva, del conocimiento de la existencia de Dios; ésta la ha completado de algún modo [gracias a] sus conocimientos en torno a los seres reales. ${ }^{20}$

Como para Kant, también para Rosmini la metafísica es un territorio reservado a la razón; pero diversamente a Kant, el roveretano sostiene que en este territorio la razón puede trabajar con éxito y no de modo fallido como sostenía el autor de la Crítica de la razón pura.

Pero de la razón Rosmini no tiene aquel concepto triunfalista que tenían los racionalistas. Su razón está estrechamente ligada al intelecto el cual, a su

\footnotetext{
${ }^{18}$ Ibid.

${ }^{19}$ Ibid., n. 511

${ }^{20}$ Ibid., n. 513.
} 
vez, está esencialmente ligado al sentido (sentimiento). A la sobrevaloración de la razón de los racionalistas que la volvían del todo autónoma e independiente respecto a los sentidos y a la experiencia sensible, Rosmini contrapone una concepción "heterónoma" de la razón, que la vincula estrechamente a la experiencia sensorial.

Pertenece a la razón, además del estudio de la metafísica, el de la lógica y el de la ideología. Doble es, en efecto, la reflexión que se puede efectuar en torno al ser: una lo ve como inicio de todas las ideas, en cuanto es "lo primero conocido", y esto pertenece a la ideología; la otra reflexión lo considera, en cambio, como inicio de todas las cosas, en cuanto el ser es "lo primero ontológicamente" y esto pertenece a la ontología. He aquí cómo Rosmini justifica esta división de la filosofía en ideología y en ontología en un bello pasaje de la Teosofía: "el ser inicial es entonces inicio tanto de lo escible como de lo subsistente; pero con esta diferencia, que el ser inicial respecto a lo escible se puede llamar también principio, cuando se considera en su virtualidad, esto es, porque contiene implícitamente todas las cosas inteligibles. Ya hemos dicho que este ser se ve en la idea, aunque se lo considere abstrayendo de la idea, por lo que cuando se toma después como inicio del orden ideal, se encuentra que todo este orden es en él mismo ingenerado, y de él se extrae, como el filo del riachuelo, mientras se den las condiciones; por lo que cuando se considera como inicio del ser real este inicio es puro antecedente a esta forma del ser, y lo real no se puede extraer de él si no se le agrega un acto, que sale de la esfera de la idea, en el que el ser ideal se contempla. El ser inicial, entonces, se conoce como inicio del orden ideal, considerándolo sólo en relación con la forma ideal, porque es la que tenemos junto con él y en la cual lo vemos; pero, para conocer también como inicio de la realidad, no basta que lo consideremos en relación con la idea que se nos da con él, sino que debemos paragonarlo al sentimiento real, el cual exige un principio como causa real que está fuera de aquella primera idea $[\ldots]$ ". ${ }^{21}$

\section{La ontología}

De la ideología, donde se ha estudiado el origen y naturaleza de las ideas, en articular de la idea de ser, Rosmini pasa a la Ontología, en la que se propo-

${ }^{21}$ Teosofia., ed. Nazionale, I, n. 287. 
ne un doble objetivo: 1) "procurarse la Teoría universal del ente (ser)"22; 2) "demostrar los límites necesarios de esta resolución humana". ${ }^{23}$

Siguiendo el ejemplo de Suárez y Wolff, Rosmini divide la metafísica en dos partes: una parte general, que estudia al ser en general, y es la que corresponde a la ontología; y una parte especial, que estudia las tres principales realizaciones del ser, Dios, el hombre y el mundo, que son respectivamente el objeto de la teología, la antropología y la cosmología.

Además, siguiendo el ejemplo de Kant, pero precisamente para tomar posición contra él, Rosmini pretende demostrar los límites de metafísica, límites reales pero que no vuelven vana su investigación.

Según Rosmini los problemas fundamentales de la ontología son cinco: 1) encontrar la conciliación de las manifestaciones del ente(ser) con el concepto del ente (ser); 2) encontrar una razón suficiente de las diversas manifestaciones del ente (ser); 3) encontrar la ecuación entre el conocimiento intuitivo y el de predicación; 4) conciliar las antinomias presentes en el pensamiento humano; 5) qué cosa es ente (ser) y qué cosa es no ente (no ser). ${ }^{24}$

Rosmini adopta los términos "ente" y "ser" como sinónimos e intercambiables. Sobre este punto su lenguaje ontológico corresponde más al de Aristóteles que al de Tomás de Aquino, el cual generalmente distingue entre el ente y el ser: el ser (actus essendi) es la actuación plena y absoluta de la perfección del ser, mientras que el ente es "aquello que posee el ser" (id quod habet esse) y es por tanto una participación del ser.

La exploración del misterio del ser, insiste Rosmini, debe ser gradual, porque la inteligencia humana "no llega a la completa teoría del ser con un solo acto de reflexión, sino con muchos, y por ende necesita romper el pensamiento en una serie de vastísimas proporciones particulares y universales vinculadas entre sí antes de llegar a lo que llamamos pensar absoluto, donde está el ápice de la Ontología". ${ }^{25}$

\section{Los seis pasos de la ascensión ontológica}

La ascensión hacia el ser es larga, difícil y peligrosa. No nos zambullimos en el ser, sino que se le conquista gradualmente. Sobre este punto Rosmini parece alinearse con aquellos que construyen la metafísica desde lo bajo; pero

\footnotetext{
${ }^{22}$ Ibid., n. 72

${ }^{23}$ Ibid., n. 76.

${ }^{24}$ Ibid., n. 74

${ }^{25}$ Ibid. n. 78.
} 
no es así, porque lo que Rosmini pone de inicio en su ontología no es todavía una indagación metafísica en torno al fundamento real de los entes que encontramos en nuestra experiencia, sino una indagación gnoseológica. Rosmini pretende explicar cómo nuestra mente, partiendo del concepto mínimo del ser, el ser indeterminado que ella posee desde siempre, se llega a elevar hasta el concepto del ser ideal, la esencia del ser. Que tal sea su objetivo lo dice claramente en un texto muy significativo de la Teosofía, que vale la pena leer completamente. Escribe ahí el roveretano:

Tenemos un punto firme desde el cual comenzar la Ontología (la ideal del ser y el sentimiento); y un medio, por el cual desde este punto firme podemos movernos lazándonos siempre a nuevas cogniciones (el ser ideal, la esencia del ser); y finalmente sabemos que nos es lícito proceder de una de estas cogniciones a otras mediante proposiciones conectadas entre sí, con la seguridad de que cada una, cuando responde a las leyes de la antigua y eterna lógica, es verdadera, y todas juntas mediante las susodichas conexiones pueden darnos aquel sistema de la verdad que buscamos.

Es lo único que queremos agregar a la ciencia ontológica, que justamente porque todos los juicios y las proporciones particulares tienen algo negativo, ninguna de las cuales nos hace conocer completamente al ser, la Ontología que se propone vincular una serie de proposiciones que nos permita alcanzar la teoría del ser es la que perfecciona al mismo saber humano, y por ello se puede llamar al mismo tiempo la teoría del saber. ${ }^{26}$

En consecuencia, el punto de partida es el ser indeterminado, cargado de infinitas posibilidades: "la mente intuye al ser indeterminado; el ser indeterminado es el primer objeto que se asoma a la Ontología, y es su punto de partida". ${ }^{27}$

En la ascensión ontológica Rosmini distingue seis pasos. Son los pasos que del ser máximamente indeterminado llevan hacia el ser máximamente determinado.

1) El primer paso hacia la determinación del ser indeterminado es el impacto de la mente con los entes finitos reales. Gracias a tal encuentro la mente comienza a descubrir algunas determinaciones del ser,

así conoce, antes que nada, al ser indeterminado, porque conoce en alguna medida la naturaleza de sus determinaciones. Entonces, de la percepción de los entes

${ }^{26}$ Ibid., n. 79.

${ }^{27}$ Ibid., n. 81 . 
finitos recibe una primera ilustración el ser indeterminado, que está presente naturalmente en la mente humana, y entonces sólo así puede comenzar el discurso de la mente, que exige pluralidad de noticias, puesto que no se conoce el solo ser con la posibilidad de sus determinaciones y sus términos en universal, sino que además de eso se conoce alguno de estos términos, y por ello se conoce en parte la naturaleza de aquel al que se refiere la posibilidad, o sea, la naturaleza de alguna determinación del ser. ${ }^{28}$

2) En el segundo paso la mente obra una confrontación entre las posibilidades limitadas del ser tal como se encuentran en las realidades finitas y la posibilidad universal, que presenta al ser mismo. A partir de esta confrontación el ontólogo revela: a) que las realidades finitas consideradas como determinaciones posibles del ser no agotan la posibilidad universal del ser, la cual no admite límite alguno; b) y además revela que el ser con toda su posibilidad infinita, sería, aunque no existiera en aquellas realidades: por ello estas realidades no constituyen la esencia del ser, no son necesarias al ser, por lo que se les llama contingentes. ${ }^{29}$

3) El tercer paso consiente a la mente el obtener algún conocimiento del ser infinito y necesario mediante la analogía, puesto que todos los entes ("los términos del ser") tienen igualmente por principio al ser y dependen de la naturaleza del ser, y al menos algunos elementos de estos términos finitos deben necesariamente encontrase en el ser mismo. "Con estas y semejantes reflexiones alcanza la reflexión ontológica a formarse una doctrina en torno a las determinaciones y a los términos en universal del ser". ${ }^{30}$

4) La analogía consiente dar un paso ulterior, y es el siguiente: "el ser no puede ser en sí mismo si no está plenamente determinado, y por tanto debe tener determinaciones y términos propios y necesarios, a los que aplica la doctrina universal en torno a la naturaleza de los términos extraída de los términos finitos por analogía"; y además "los términos propios y necesarios del ser no pueden tener limitación alguna, porque el ser no los tiene, y deben entrar también ellos a constituir la esencia del ser, de otra manera se caería en contradicción, a saber,

\footnotetext{
${ }^{28}$ Ibid., n. 86.

${ }^{29}$ Cf. Ibid., n. 87.

${ }^{30}$ Ibid., n. 88 .
} 
el ser sería negado, cuando su naturaleza implica que no puede no ser". ${ }^{31}$

5) El quinto paso "es el que establece la necesidad de los términos propios del ser". 32

6) El sexto y último paso "remueve de estos términos todo aquello que no les conviene, como sería justamente la limitación". ${ }^{33}$

Esta ascensión hacia la plenitud del ser, concluye Rosmini, permite a la mente también alcanzar la definición del concepto de Dios: "de este modo la mente llega a la teoría del ser absoluto, que tiene los caracteres de la divinidad, los cuales faltaban todavía al ser indeterminado". 34

Quien tiene una cierta familiaridad con la metafísica de santo Tomás puede fácilmente constar que los pasos de la ontología rosminiana coinciden substancialmente con los de la ontología tomasiana: se parte del estudio de los entes finitos, se eleva al ser absoluto y luego, con el método de la analogía, con sus dos momentos de la afirmación (vía positiva) y la remoción (vía negativa) se busca determinar los atributos del ser absoluto y, por tanto, de Dios. Pero mientras la resolutio de santo Tomás tiene un carácter claramente real y metafísico, la resolutio de Rosmini es de estampa metafísico-gnoseológica, la exploración de Rosmini no se desenvuelve en el ámbito de la realidad (de los entes y del ser), sino en el ámbito de las posibilidades del ser indeterminado (que están todas por determinar) y las posibilidades del ser absoluto (que son todas determinadísimas).

\section{El círculo ontológico y la circumnavegación del ser}

Trazando el itinerario que debe recorrer el ontólogo para efectuar su difícil ascensión hacia el ser, Rosmini brinda dos importantes precisiones que caracterizan ulteriormente su ontologia en sentido neo-platonizante.

La primera precisión se refier al círculo ontológico.

La ontologia es claramente una hermenéutica del ser, o sea, una interpretación de los documentos que nos presenta la realidad con vistas a comprender el ser. Al hablar de Schleiermacher, padre de la hermenéutica, hemos visto que uno de los cánones fundamentales de su doctrina de la interpertación es

\footnotetext{
${ }^{31}$ Ibid., n. 89.

32 Ibid.

${ }^{33}$ Ibid.

${ }^{34}$ Ibid.
} 
el "círculo hermenético", el cual prescribe presentar las partes a la luz del todo y visceversa, estudiar del todo a la luz de las partes. Rosmini se sirve de este cánon en su hermenéutica del ser y lo describe egregiamente en el texto siguiente de la Teosofía:

El razonamiento ontológico se desenvuelve necesariamente en círculo, puesto que el objeto de la Ontología es todo el ente, y el razonamiento no puede ascender a la cognición del todo sin recurrir a la doctrina de las partes que lo componen y no se pueden conocer las partes sin recurrir a la cognición del todo. El todo y las partes son correlativas; y los correlativos son entendidos por la mente con un solo acto. Pero el razonamiento necesita examinar los términos de la correlación y no puede examinarlos a ambos en un mismo momento. Quien quisiera hablar del todo sin analizarlo, habría terminado el discurso con una sola palabra, puesto que después de haber pronunciado la palabra todo, no podría ya decir otra cosa [... ]. Por ende, hay en este orden de razonar un círculo inevitable, habiendo necesidad de la teoría del ente finito para establecer la teoría del ser en universal y en absoluto, y hay necesidad de estas dos teorías para dar la del ente finito. ${ }^{35}$

El círculo del que habla Rosmini es el círculo de ascensus y del descensus practicado por los neoplatónicos y por el mismo santo Tomás en el componente neoplatónico de su pensamiento.

La segunda precisión clarifica ulteriormente la naturaleza del itinerario ontológico rosminiano. No se trata de una ascensión como hemos descrito hasta aquí, y tampoco de una segunda navegación como la definía Platón, sino de una circumnavegación. La ontología rosminianina no deja la planicie de los entes para subir sobre la veta del ser, y ni siquiera abandona el puerto de los entes para alcanzar el lejano puerto del ser, sino que todo es un viaje interno al ser y dentro del mar del ser. He aquí el bello texto de Rosmini sobre este asunto:

Nuestro razonar, entonces, en la exposición de la Teosofía, será similar al proceder de aquellos que navegan en un estanque, los cuales, a pesar de surcar el estanque con su navecita en una sola línea, sin embargo, o vayan o vengan o se muevan por una recta o por líneas curvas serpenteando, nunca salen del estanque, y si no estuviera todo el estanque no podrían de ninguna manera surcarlo a lo largo y ancho en las diversas direcciones, aunque tracen siempre líneas angostísimas en dichas aguas. Así, aunque nosotros vayamos razonando por las diversas partes de estas obras en distintos asuntos, no podremos salir jamás del mar del ser que exploramos, y aunque estrecho sea el camino que nos abrimos en él con nuestro casco,

${ }^{35}$ Ibid., nn. 91-92. 
nos convendrá tener presente siempre todo el ser no en la lengua sino en la mente, porque toda palabra nuestra, todo tratamiento parcial lo exige necesariamente como un presupuesto con el fin de que pueda ser dicha por nosotros o entendida por los otros. ${ }^{36}$

Para mover la navecita del pensamiento dentro del mar del ser y conducirla del ser indeterminado al ser absoluto a través de los entes, el ontólogo requiere de buenos remos, y tales son los principios primeros que Rosmini reduce a tres: el principio de cognición, el principio de no-contradicción, y el principio de causalidad. El primero dice: "el objeto del pensamiento es el ser". Este principio, según Rosmini, "es el principio de todos los principios, la ley de la naturaleza inteligente, la esencia de la inteligencia". ${ }^{37}$ Del segundo principio el roveretano da la siguiente definición: "no se puede pensar el ser y al mismo tiempo el no ser". ${ }^{38}$ En fin, para el principio de causalidad adopta la siguiente formulación: "no se puede pensar en una nueva entidad sin una causa". 39

Mientras los primeros dos principios siempre han sido compartidos por casi todos los filósofos (entre ellos los escépticos), el tercero, el de causalidad, en la época moderna había sufrido pesados ataques de parte de Hume y Kant. Para el primero se trataba de una ficción de la memoria y la fantasía, y para el segundo de un principio a priori del intelecto.

Puesto que sobre el valor objetivo del principio de causalidad se apoya toda la metafísica, antes de proceder a su construcción es necesario demostrar que su valor objetivo es absolutamente innegable. Es lo que buscó hacer Rosmini en diversos escritos, demostrando que el principio de causalidad se funda directamente sobre el principio de no contradicción. En efecto, decir que un suceso no es causado equivale a decir que no es un suceso, porque por suceso se entiende "todo aquello que comienza". He aquí en breve una argumentación de Rosmini:

Para demostrar que un suceso sin una causa no se puede pensar, conviene demostrar que el concepto de un suceso carente de una causa implica contradicción. Cuando esto sea demostrado entonces se tendrá el principio de causa deducido del principio de contradicción, he aquí cómo se demuestra. Decir que aquello que no existe obra es contradictorio. Pero un suceso sin causa equivale a decir: lo que no existe, obra. Por ende, un suceso sin causa es contradictorio [...] en consecuencia, el principio

\footnotetext{
${ }^{36}$ Ibid., n. 96.

${ }^{37}$ Nuovo saggio IV, n. 568.

${ }^{38}$ Ibid.

${ }^{39}$ Ibid.
} 
de causa desciende del principio de contradicción, así como estos dos principios descienden del principio de cognición, y no es más que la idea de ser aplicada, la cual toma forma de principio y se expresa en una proposición, cuando ella se considera en relación con el razonamiento del hombre, del cual ella es la causa universal. ${ }^{40}$

\section{Las tres formas primitivas del ser y el sintetismo}

Múltiples son las manifestaciones del ser. Tarea del ontólogo es reducirlas a algunas manifestaciones fundamentales. Aristóteles con su célebre doctrina de las categorías las había reducido a diez. La clasificación aristotélica se refiere tanto a la lógica como a la metafísica; en efecto, las diez categorías son tanto los diez modos de concebir al ser como los diez modos de realizar al ser. Rosmini pretende efectuar una clasificación todavía más breve, reduciendo todas las manifestaciones del ser a tres formas primitivas, a las que da los nombres de real o subjetiva, forma ideal u objetiva y forma moral.

Creo que sobre la clasificación en sí no existen problemas: ella corresponde a la clasificación de la verdad, la cual asume tres formas principales, a saber, lógica, ontológica y moral. Lo que, en cambio, genera problema es la pretensión de Rosmini por establecer no sólo que las formas del ser son tres, sino que sólo y necesariamente deben ser tres, ni más ni menos. En otras palabras, lo que es problemático es la deducción de las tres formas. Sobre este punto el roveretano no sigue a Aristóteles, el cual había obtenido su clasificación no con el método deductivo sino con el inductivo. Se había servido del mismo procedimiento con el que había obtenido la clasificación de los animales y las plantas, esto es, basándose exclusivamente en la observación empírica. En vez de Aristóteles, Rosmini sigue a Kant, el cual había deducido sus categorías de los doce tipos de juicios del intelecto, pero efectuando una vía totalmente nueva e inusitada. Deduce las tres formas del ser del modelo del misterio trinitario: en la Trinidad el Padre genera al Verbo; y el Verbo y el Padre se ligan entre sí mediante el vínculo del eterno y subsistente Amor que es el Espíritu Santo. He aquí el pasaje en el que Rosmini deduce las tres formas primitivas del ser:

Llamamos formas del ser al ser mismo que, si bien todo entero, es de modos diversos esenciales a él. ¿Existen, entonces, estas formas? El ser, por la propia

${ }^{40}$ Ibid., n. 570. 
naturaleza de ser, ¿es él de un solo modo o de varios? Y si es de varios modos, ¿es él en cada modo todo el ser? Esta es la cuestión y no se puede resolver sino por vía de la contemplación de la mente.

Ahora bien, estas formas son y decimos que son tres, es decir, que el ser como tal es idéntico de estos tres modos esenciales a él. Denominamos a estas tres formas subjetiva, objetiva y moral. Que existan las dos primeras lo dice la Ideología y las observaciones que hacíamos ahora sobre los elementos, ya que es evidente que se pueden concebir algunos de tales elementos, igualmente como existentes en sí realmente tanto como en su esencia, sin que realmente existan; y esta esencia es la forma objetiva, como la subsistencia es la forma subjetiva a la que se reduce además, como veremos, la que llamamos nosotros extrasubjetiva. Pero si el ser es idéntico en la forma objetiva y en la subjetiva, estas dos formas están unidas en la identidad del ser. Por ende, si están unidas, hay entre ellas un vínculo. Pero este vínculo no resulta de la consideración de cada una de las dos formas tomadas por separado. Por tanto, este vínculo constituye una tercera forma, en la cual el ser es. Puesto que este vínculo no es nada, entonces es él mismo ser. Y puesto que en cada una de las dos formas está el ser completo, la unión de ellas debe abrazar a todo el ser bajo una forma unidamente a todo el ser bajo la otra forma. En consecuencia, está todo el ser bajo la forma de la unión, puesto que no hay ninguna partícula del ser que sea inmune a ella, y por ello no se da distinción entre el sujeto que admite la unión y lo que permanece unido, sino que todo está unido y todo es unión [... ]. Las dos formas, entonces, una de las cuales no es la otra, sino cada una es todo el ser, deben tener una comunicación entre ellas sin confundirse. Esta comunicación supone que el ser sea por sí amado, es decir, que aquel ser que es absolutamente siendo (essente), y que es también por sí conocido, sea también por sí amado. Pero en cuanto es por sí amado, no es por sí absolutamente siendo, no por sí conocido; por tanto, el ser por sí amado es una tercera forma en la que el ser mismo es. Y justamente porque el ser por sí amado es el ser mismo que es en las dos primeras formas, ni siquiera esta tercera forma elimina la unidad perfectísima del ser.

En consecuencia, hay en el ser necesariamente una unidad perfectísima de esencia y una trinidad de formas. ${ }^{41}$

Frente a esta argumentación se puede quedar uno perplejo. No hay duda, en efecto, que existe también una forma moral del ser, que es la que corresponde al bien; pero se trata todavía de una forma ideal.

Es el mismo ser visto como fin por alcanzar. No es, por tanto, como piensa Rosmini, un fruto del encuentro entre el ser ideal y el ser real, sino es el ser en vistas a ser real, o bien el ser que en el cumplimiento de una acción perfecciona a la voluntad y mediante la voluntad al hombre mismo, y entonces se trata del ser real.

${ }^{41}$ Teosofia I, nn. 148-154. 
Entonces, es más convincente la teoría de santo Tomás, quien distingue las categorías de los trascendentales del ser. Las categorías son siempre modos limitados de expresar o actualizar al ser, mientras los trascendentales son expresiones globales del ser y por ello son convertibles entre sí, mientras que la convertibilidad es excluida de las categorías. Santo Tomás deduce los dos principales trascendentales del ser, el verum y el bonum de dos facultades espirituales del hombre: el verum expresa la inteligibilidad del ser, mientras el bonum expresa su apetibilidad.

En substancia, la doctrina rosminiana de las tres formas primitivas del ser corresponde a la doctrina tomista de los trascendentales ens, verum, bonum. En efecto, también Rosmini vincula la forma ideal al intelecto, como hace santo Tomás con el verum, y la forma moral con la voluntad y con el amor, como hace el Angélico con el bonum. Mientras que la forma real corresponde al ens real, o sea, al ser absoluto.

Pero Rosmini no llama a las formas primitivas del ser trascendentales, sino categorías, prefiriendo el lenguaje kantiano al aristotélico-tomista: "las formas inmutables e incomunicables del ser constituyen nuestras Categorías". ${ }^{42}$

La ontología trata del ser en general y no de sus concretas actualizaciones. Por tanto, una vez demostrada la necesidad de que el ser asuma las tres formas del ser ideal, real y moral, la ontología ha agotado su tarea. El estudio de las concretas realizaciones del ser corresponde a las tres grandes ramas de la metafísica especial, la Teología natural, la Antropología y la Cosmología.

Concluyendo su introducción general a la metafísica, Rosmini encuentra un nombre para su sistema y lo llama sintesismo. La razón de este nombre es tomada de la verdad de que "el ente no puede subsistir bajo una sola de las tres formas si no existe también bajo las otras dos, en cuanto que para el pensamiento humano el ente, también bajo la sola forma, se representa como siento por sí y perceptible de un modo distinto". ${ }^{4}$

¿Qué cosa decir de la hermenéutica rosminiana del ser del que hemos dado las líneas esenciales? A esta pregunta daremos una respuesta más cuidadosa y articulada al final del capítulo, luego de haber expuesto el pensamiento metafísico del roveretano en torno al hombre y Dios. Por el momento, debemos reconocer a Rosmini el mérito de haber escrito páginas memorables sobre el problema fundamental del ser, sobre el que muchos filósofos, por mucho tiempo, dejaron en el olvido, como ha sido notado por Heidegger (el cual,

${ }^{42}$ Ibid., n. 167.

${ }^{43}$ Ibid., n. 173. 
por su parte, ignora tanto a Tomás como a Rosmini, que son los dos máximos exponentes de la filosofía del ser, desde cuando el interés por la metafísica ha pasado de los griegos a los cristianos).

En la metafísica moderna (de Descartes, Spinoza, Pascal, Leibniz, Kant) la ontología prácticamente desaparecía y su propósito había sido recuperado por la gnoseología y la crítica. Así, toda la atención de los filósofos se había dirigido al sujeto cognoscente en vez de al objeto conocido, y por tanto a sus certezas más bien que a la verdad. Rosmini restituye a la ontología aquella dignidad que le compete en toda metafísica que se enfrente a lo Entero a través de la ventada del ser. Esto justifica el título de "máximo metafísico del siglo XIX", que algún historiador ha querido dar a Rosmini.

\section{La antropología filosófica}

El hombre y Dios son las dos grandes realidades en torno a las que gira la reflexión filosófica de Rosmini: el hombre es aquel sobre el cual irradia la luz del ser; Dios es aquel del cual aquella estupenda luz proviene. Así, gran parte de su producción filosófica se concentra sobre estos dos temas. Sobre el hombre se ocupa en la Antropologia in servizio della scienza morale, en la Antropologia soprannaturale, en la Psicologia, en los Principi della scienza morale. Sobre Dios trata en la Teodicea y en la Teosofia.

En su vastísimo tratamiento, Rosmini se propone responder a tres interrogantes fundamentales. ¿Quién es el hombre? ¿Quién es Dios? ¿Cuáles son las relaciones entre el hombre y Dios? Veamos antes que nada su respuesta a la primera pregunta. Como observa el mismo Rosmini ${ }^{44}$, hay dos tipos fundamentales de antropología:

-la antropología platónica que considera al hombre desde lo alto y, por ello, lo identifica con el alma y, por ende, con el espíritu;

- la antropología aristotélica que considera al hombre desde lo bajo y lo define como una especie del reino animal, esto es, como un animal racional.

Kant había utilizado ambos paradigmas. En la Crítica de la razón pura se sirve del paradigma aristotélico, pero así no llega a encontrar ninguna respuesta segura para el arduo problema de la inmortalidad del alma. En cambio, en la Crítica de la razón práctica se sirve del paradigma platónico y éste le permite salvar la ley moral, la libertad humana y la espiritualidad del alma.

${ }^{44}$ Cf. Antropologia in sevizio della scienzia morale, Ediz. Nazionale, Milán 1954, nn. 24ss. 
A pesar de los logros dualistas del pensamiento kantiano, estos no resuelven, sino que agravan la antinomia entre la posición platónica y la aristotélica.

Rosmini, que tiene un destacado sentido de la armonía, de la "unidad y totalidad", de la síntesis y la completud, considera al hombre tanto como animal como espíritu, y estudia al hombre como "sujeto en el que convienen la animalidad y la inteligencia". ${ }^{45}$ Critica, entonces, las tradicionales definiciones de Platón y Aristóteles.

Según la definición platónica, "el hombre es una inteligencia servida por órganos". Esta definición, observa Rosmini, no distingue adecuadamente al hombre del ángel; es más, se aplica más al ángel que al hombre, porque el ángel es un ser dotado de "un cuerpo como una máquina sin informarlo por sî". 46

Según la definición aristotélica, "el hombre es un animal racional". A esta definición Rosmini reprocha los siguientes defectos: 1) diciendo que es un animal racional se expresa la parte inteligente de este animal, pero se descuida la parte volitiva, que en el hombre no es menos importante que la primera; 2) decir simplemente que "el hombre es un animal racional" puede "inducir a creer que en el hombre el sujeto es un animal y nada más, y que la racionalidad no es otra cosa que una propiedad o facultad o atributo de este animal". ${ }^{47}$

Contra estas dos definiciones, que Rosmini considera unilaterales, estando la primera muy desbalanceada hacia el espíritu y la segunda hacia la animalidad, propone la siguiente definición del hombre: "un sujeto animal, intelectivo y volitivo". ${ }^{48}$ Como precisa el propio Rosmini, esta definición es más completa que la platónica y la aristotélica porque incluye, además del elemento intelectivo, también el volitivo. Y en segundo lugar porque coloca al sujeto como fundamento de todas las cualidades del hombre: la animalidad, la inteligencia y la voluntad. "De tal modo que estas cualidades tienen una misma relación con el sujeto, y una no es privilegiada sobre las otras; es decir, aquel principio que forma la unidad humana se distingue de la animalidad, de la inteligencia y de la voluntad; vienen a ser las tres igualmente comunes; así que aquel que siente como animal es el mismo que entiende y quiere como inteligente y volente". 49

\footnotetext{
${ }^{45}$ Epistolario IV, p. 614.

${ }^{46}$ Antropologia, cit., n. 26.

${ }^{47}$ Ibid., nn. 27 y 31.

${ }^{48}$ Ibid., n, 34

${ }^{49}$ Ibid.
} 
Más adelante Rosmini propone una segunda definición más amplia, que explicita algunos elementos característicos de su antropología. He aquí la segunda formulación: "El hombre es un sujeto, animal, dotado de la intuición del ser ideal-indeterminado, y de la percepción del sentimiento fundamentalcorpóreo, y agente de un modo conforme a la animalidad y la inteligencia que posee". 50

Como se ve, en ambas definiciones Rosmini evita escrupulosamente hablar de alma y cuerpo, los dos términos con los que siempre había trabajado la antropología clásica. Se sirve del lenguaje que es plenamente conforme a su ideología, la cual, como sabemos, pone la intuición del ser ideal como base de todo. Entonces, el hombre es antes que nada la inteligencia que apresa al ser ideal. Pero, puesto que ésta es una intuición abstracta, pura forma del conocer, el hombre alcanza lo real mediante el sentimiento fundamental-corpóreo. Aquí están, entonces, los dos principales ingredientes de la antropología rosminiana: la intuición del ser ideal, que es propiedad del espíritu, y el sentimiento fundamental-corpóreo, que es propiedad de la animalidad.

Luego de haber definido al hombre, Rosmini afronta el análisis de su parte animal. Aquí su atención se concentra sobre los instintos que son los dinamismos en los que toma al cuerpo y se expresa el sentimiento fundamental corpóreo. La actividad del animal, según el roveretano, se puede reducir a dos formas: la acción con la que el animal se aumenta a sí mismo y aquella con la cual consuma su entera energía, o sea, "aquella con la cual concurre a la producción del sentimiento y con la que obra tras el sentimiento ya producido". 51 La primera es llamada instinto vital y la segunda instinto sensual.

El instinto vital es, se podría decir, aquel comportamiento del alma sensitiva que continuamente está distendida en producir la vida, en reparar los daños y las pérdidas que el animal sufre. "El instinto vital en todas sus operaciones no tiene otro objetivo que producir el sentimiento excitado y único, y así dar vida al cuerpo". 52 Por ello, el instinto vital es esencialmente vivificador.

En cambio, el instinto sensual va en busca de sensaciones y procura las sensaciones de la vista, del oído, del gusto, del olfato y el tacto.

Como se ha dicho, estos instintos son los canales del sentimiento fundamental corpóreo. Como todas las ideas presuponen la idea de ser, así todas las sensaciones presuponen el sentimiento fundamental corpóreo. La idea del ser

\footnotetext{
${ }^{50}$ Ibid., n. 37.

${ }^{51}$ Ibid., n. 369.

${ }^{52}$ Ibid., n. 403.
} 
es lo primero pensado o primer lógico, además de ontológico; el sentimiento fundamental corpóreo es el primer psicológico o sentido, del que las sensaciones son modificaciones, y que vuelve posible la percepción de los objetos externos mientras nos da la conciencia de nosotros como unidos a un cuerpo; nos pone en contacto con las cosas y nos pone como sensibilidad pura de nosotros a nosotros mismos.

En el Tercer libro de la Antropologia in servizio della scienza morale, Rosmini estudia la parte espiritual (la espiritualidad) del hombre, la cual se sirve de dos actividades: intelectiva y volitiva.

La actividad intelectiva, además de con el intelecto, se ejerce también con la razón. Mientras el intelecto es pura intuición del ser ideal, la razón aplica el ser ideal a las sensaciones, y de este modo alcanza el mundo real. La razón tiene más funciones: la percepción, la abstracción, la deducción de las ciencias puras (o sea, las que se refieren a los seres ideales) y la deducción de las ciencias completas (esto es, las que se refieren a los seres reales).

Lo que caracteriza a la voluntad humana es el ser libre. La libertad es una facultad con la que el ser inteligente elige un bien verdadero o aparente con pleno dominio del propio acto. La libertad puede ser, como es de hecho en el hombre viator, libertad bilateral. Ésta se da cuando el hombre está colocado en la alternativa de elegir entre un bien objetivo conocido intelectivamente y un bien subjetivo que estimula y llama placenteramente su sensitividad. Si el acto de elección es conforme al bien objetivo, o bien es diforme, la libertad se vuelve meritoria o demeritoria. La libertad es la facultad más sublime del hombre, la que le confiere más alta dignidad.

$\mathrm{La}$ animalidad y la inteligencia, con sus respectivas funciones, no son dos binarios que corren paralelos sin encontrarse nunca, sino dos actividades que pertenecen al mismo sujeto, al mismo individuo. Está en la definición del sujeto humano como persona - del cual habla Rosmini en el libro IV de la Antropología - que se revela el espíritu cristiano de su filosofar.

Como todos sabemos, el concepto de persona es una de las grandes conquistas del cristianismo. Dice esencialmente que el ser humano pertenece al orden del espíritu, que es el orden de la inteligencia y la voluntad. El fulcro de la antropología rosminiana se halla en el capítulo dedicado a la definición de la persona. Es aquí que Rosmini elabora su doctrina metafísica de la persona en general y de la persona humana en particular. ${ }^{53}$ "Se llama persona a

${ }^{53}$ Cf. G. Bozzetti 1946. 
un individuo substancial inteligente, en cuanto contiene un principio activo, supremo e incomunicable". 54

El concepto de persona dice más que el de sujeto. Sujeto dice simplemente un principio supremo de actividad en un individuo sentiente cualquiera, sea inteligente o no. En cambio, persona dice un principio supremo en un individuo inteligente. Así que la diferencia entre sujeto y persona es la misma que entre el género y la especie.

Las propiedades principales de la persona son las que aparecen en su misma definición: 1. Principio activo, 2. Supremo, 3. Incomunicable.

En primer lugar, se trata de un principio activo. Aquí activo es entendido por Rosmini en su significado más extenso, "en el cual abraza en cierto modo a la pasividad, así que la persona es aquel principio al que se refiere y de que parte finalmente toda la pasividad y toda la actividad del individuo". 55

En segundo lugar, es un principio supremo, esto es, "tal que en el individuo no se encuentre otro que le esté por encima y por el que cambie de existencia; es más, es tal que hay en el individuo otros principios que dependen de él y no pueden subsistir en aquel individuo sino por el nexo que tienen con él". ${ }^{56}$

Por último, debe ser incomunicable: esta propiedad deriva de la noción de individuo, dado que "el individuo no puede comunicarse sin dejar de ser aquel individuo que era primero, y del mismo modo debe entenderse la incomunicabilidad del sujeto y la persona". 57

La persona, incomunicable, "es esencialmente una", esto es, toda persona es una unidad, una singularidad irreductible; hay multiplicidad en las cosas, no en las personas. Toda persona es por sí misma e irrepetible; varias personas son unidades que forman una masa. La existencia de toda persona como persona "comienza y termina en sî́; cada una de ellas es "un uno subjetivo"; de este uno, que es la persona singular, no existen dos ejemplares, sino uno solo.

En cuanto principio activo supremo inteligente, la persona es "causa de las propias acciones" y es, por tanto, autónoma. De aquí también la completud de la persona: "el ente que está dotado de inteligencia es un ente completo, y por ello esta sola forma de entes, los inteligentes, merecen la denominación aristotélica de entelequias, que significa perfección, denominación ontológica

\footnotetext{
${ }^{54}$ Rosmini, Antropologia, n. 832.

${ }^{55}$ Ibid., n. 834.

${ }^{56}$ Ibid.

${ }^{57}$ Ibid., n. 836.
} 
porque trata de la íntima constitución de los entes mismos". Por tanto, todo lo que es y no tiene inteligencia es relativo a la persona, que es un ente inteligente. De aquí la fuerte afirmación de la Logica: "lo que es pero no es persona, no puede estar sin que haya una persona: principio de persona". En este sentido, sólo a la persona conviene la existencia, a ella es relativo todo lo real, que es pertenencia de la persona.

La unidad del ser humano proviene de su principio espiritual, el cual está en grado de agregarse a sí e informar al principio material.

Aquí se asoma el eterno problema de las relaciones entre alma y cuerpo, o entre espiritualidad y animalidad como a veces ama expresarse Rosmini. A este difícil problema, el roveretano dedica muchas atenciones tanto en la Antropologia in servizio della scienza morale como en la Psicologia.

El problema de las relaciones entre alma y cuerpo es el más clásico y debatido de todos los problemas antropológicos. Rosmini conoce perfectamente toda su historia y las principales soluciones: las de Platón, Aristóteles, Agustín, Tomás, Descartes, Malebranche, Leibniz, etcétera.

El peligro en el que incurren casi todos los filósofos es el de acentuar excesivamente la discontinuidad entre alma y cuerpo (es el caso de los platónicos) o bien el de poner demasiado el acento en su unión (es el caso de los aristotélicos): los platónicos propenden por una unión accidental; mientras que los aristotélicos afirman la unión substancial. Este riesgo se puede conjurar si el juego se juega con tres cartas en vez de dos: si al cuerpo y al alma se agrega el espíritu, y se concibe el espíritu no como una cualidad del alma, sino, viceversa, se considera al alma como una función del espíritu. Ésta es, substancialmente, la solución que abraza Rosmini, aunque su lenguaje en este punto resulta a veces incierto y oscilante.

He aquí algunos pasajes en los que Rosmini habla del espíritu como principio ontológico fundamental, que unifica y sostiene todo el ser humano:

Este principio uno y simplísimo, el cual por un lado subyace a la pasividad producida por la acción del cuerpo, por la otra subyace a la pasividad, o mejor receptividad, del ser universal, es justamente aquello que se llama espíritu humano. En el espíritu humano, principio sentiente-intelectivo, yacen virtualmente todas las potencias, que luego, dadas las ocasiones oportunas, se distinguen manifestándose con determinadas operaciones. Porque el acto mismo con el cual ese espíritu existe, es la virtud universal de obrar en tantos modos diversos, en cuantas actividades luego desarrolla y manifiesta. ${ }^{58}$

${ }^{58}$ Ibid., nn. 529-530. 
Por otra parte, todo aquello que pertenece al intelecto es inmune de cualquier concreción y contacto con el cuerpo, y por ello constituye por sí solo una sustancia espiritual. $^{59}$

Una substancia que no tenga ninguna propiedad del cuerpo y la materia, se llama espiritual, o sea, espíritu: por tanto, el alma humana es un espíritu. ${ }^{60}$

Como sabemos, la antropología rosminiana está construida desde lo alto. Pero diversamente a las construcciones platónicas que se sirven sólo de los elementos y, así, se encuentran en grandes dificultades cuando se trata de explicar las relaciones entre alma y cuerpo, Rosmini, introduciendo el espíritu como tercer elemento distinto tanto del alma como del cuerpo, está en grado de ofrecer una concepción profundamente unitaria del ser humano.

Rosmini critica expresamente las dos versiones más modernas del platonismo: la armonía preestablecida (Leibniz) y el ocasionalismo (Malebranche). Según el roveretano, con estas hipótesis "no podremos tener ninguna cognición del cuerpo, porque toda cognición nuestra del cuerpo se reduce a hacernos conocer que el cuerpo es término del sentimiento del alma; y por ello en la noción misma de cuerpo se implica como esencial una relación de unión con el alma" ${ }^{61}$ De las relaciones entre alma y cuerpo, Rosmini se limita a dar una explicación psicológica. Su tesis es que "el alma y el cuerpo están unidos por medio del sentimiento". 62 "En la primera y fundamental percepción del término corpóreo consiste justamente el nexo del alma con el cuerpo, que constituye al hombre como ente racional". ${ }^{63}$ A esta percepción fundamental Rosmini da el nombre de sentimiento fundamental.

El sentimiento fundamental con el que el alma conoce el propio cuerpo tiene una doble implicación, intelectiva y sensitiva. Escribe Rosmini:

La unidad del hombre consiste en un sentimiento único, propio del principio racional, en el cual el sentimiento único no es sólo el sentimiento animal, sino también el sentimiento racional, de modo que en éste se contiene como en el más se contiene el menos; así que el hombre, en su primer estado, no tiene ya más sentimientos, es decir, el sentimiento animal y racional, sino un único y simplísimo sentimiento, que tiene un principio y un término. Tiene un principio, que es el mismo principio racional, y tiene un término, que es la idea del ser, y en aquel ser ve el sentimiento

\footnotetext{
${ }^{59}$ Ibid., 502.

${ }^{60}$ Psicologia, n. 133.

${ }^{61}$ Ibid., n. 252.

${ }^{62}$ Ibid., n. 250

${ }^{63}$ Teosofia, cit., III, p. 11.
} 
animal, que experimenta; ya que en la percepción sucede, para decirlo de nuevo, que del subsistente sentido y del ser se forme un solo ente, objeto del único principio racional. Esta percepción primitiva y fundamental de todo lo sentido (principio y término) es el tálamo, por decir así, donde lo real (sentimiento animal-espiritual) y la esencia, que se intuye en la idea, forman una sola cosa; y esta cosa es el hombre. $^{64}$

Pero el alma humana no es únicamente sensitiva, sino también intelectiva. Es un principio intelectivo y sensitivo al mismo tiempo. En cuanto es un principio sensitivo tiene por término el propio cuerpo; pero debido a que el principio intelectivo está unificado con el sensitivo, de manera que es un solo principio con dos actividades, por ello el alma intelectiva y sensitiva, o en una sola palabra el alma racional, tiene por su término el cuerpo. En cuanto es sensitiva tiene como término lo sentido, en cuanto es intelectiva tiene como término lo entendido: por lo tanto, el cuerpo es un término del alma humana sentido-entendido. En consecuencia, hay una percepción intelectiva del propio cuerpo, primigenia e inmanente, y en esta percepción consiste el nexo entre el alma humana y el cuerpo. ${ }^{65}$

Al problema de la relación entre el alma y el cuerpo está estrechamente vinculado el de la espiritualidad e inmortalidad del alma, que es el problema más espinoso de la ontología antropológica. ¿El alma mueve al cuerpo, como parecen sugerir las apariencias inmediatas, o bien se va y regresa a la patria beata?

Existe un amplio acuerdo entre los filósofos que el alma o en su totalidad (Platón) o en parte (Aristóteles) es por naturaleza espiritual. Rosmini asignando al alma el estatuto de persona y por ende de un ser en cuyo supósito (sujeto, principio último) es de orden espiritual, se coloca con los que afirman la naturaleza espiritual del alma humana y defienden la inmortalidad personal.

El argumento principal en el que Rosmini funda la inmortalidad del alma está estructurado sobre una falsilla del argumento platónico de la afinidad (parentela) del alma con el mundo de las Ideas y con el argumento agustiniano de la afinidad (parentela) del alma con la Verdad. Rosmini deriva la inmortalidad del alma de su afinidad (parentela) con la idea del ser y ultimadamente con el ser mismo. He aquí un par de textos en los que se propone esta argumentación:

No siendo el alma humana sino un principio sentiente que tiene por término de su sentir al ente en universal, es manifiesto que ateniéndose ésta inmóvilmente unida

\footnotetext{
${ }^{64}$ Psicologia, n. 264.

${ }^{65}$ Sistema filosófico, n. 140.
} 
al ente y éste siendo eterno, simplísimo, fuera del espacio y el tiempo, también ella, el alma, se hace partícipe de todas estas noblísimas prerrogativas. ${ }^{66}$

Hemos visto que los términos (los elementos constitutivos del hombre) son dos, el cuerpo y el ser en universal. Ahora bien, ¿qué ente extraño podría destruir estos términos del ente del hombre? Los entes extraños son Dios y las cosas contingentes. En cuanto a Dios, hemos ya supuesto que no destruya ninguna de las cosas que ha creado; por ende, la destrucción del hombre no puede venir de Dios. Pero, ¿qué cosas contingentes pueden destruir la actividad del hombre? ¿Qué cosas pueden destruir los dos términos del acto primero por el que el hombre es? El cuerpo del hombre, uno de los términos, es un complejo de elementos orgánicos del modo más pleno y, por ello, individuados. Ahora bien, las fuerzas de la naturaleza pueden desunir esta organización y, en consecuencia, destruir con ella el sentimiento animal propio del hombre. Pero sobre el ser en universal todas las fuerzas de la naturaleza nada pueden; porque el ser universal es impasible, inmutable, eterno, no subyace a la actividad de ningún ente. Por tanto, aquella virtud con la cual el hombre intuye al ser en universal no puede perecer. Pero esta virtud, este primer acto, es el alma intelectiva; en consecuencia, el alma intelectiva no puede dejar de existir en su propia individualidad, ya que tiene la realidad propia suya que la individua, lo que vulgarmente se expresa diciendo que es inmortal. ${ }^{67}$

Hasta aquí hemos examinado la respuesta de Rosmini a la primera interrogante: ¿quién es el hombre? Pasemos ahora al segundo: ¿quién es Dios?

\section{La teología natural}

Sobre la cuestión de Dios se ocupa la teología natural. Ella se distingue de la ontología. Esta trata sobre el ente considerado en toda su extensión así como es conocido por el hombre: "trata del ente en su sencia y en las tres fomas en las que la esencia del ente es, la forma ideal, la forma real y la forma moral". En cambio, la teología natural "trata sobre el ente como es en sí, en cuanto nuestra mente se percate de que el ente, además de aquella parte que se nos manifiesta a nosotros, se extiende más allá; trata, en suma, sobre el ser absoluto, sobre Dios". 68

En la teología natural Rosmini estudia la existencia, la naturaleza, los atributos y las operaciones de Dios. En efecto, luego de que Hume y Kant habían sostenido que a la razón le está cancelada toda posibilidad de demostrar la existencia de Dios, este problema que en la filosofía medieval y moderna

\footnotetext{
${ }^{66}$ Antropologia, n. 820.

${ }^{67}$ Psicologia, n. 679.

${ }^{68}$ Sistema filosofico, n. 176.
} 
había sido agilmente resuelto o con pruebas a priori (Anselmo, Descartes, Spinoza, Leibniz) o a posteriori (Tomás, Escoto, Locke, Hegel), se había vuelto particularmente arduo y espinoso. Rosmini, consciente de la importancia del argumento y sus dificultades, no dejó de elaborarlo de mil maneras en muchos de sus escritos, tanto que alguno ha podido escribir que en Rosmini se advierte el aguijón de la exitencia de Dios. ${ }^{69}$ Efectivamente, el roveretano nunca se cansa, cualquiera que sea el argumento que esté tratando, de poner en relieve nuevas formulaciones racionales referentes a la exietencia del Absoluto, donde a menudo recurre, con el tono entusiasta del investigador apasionado, a la exclamación satiscfecha: ¡he aquí una nueva prueba! El mismo aguijón cuando todavía era joven lo había inducido a proponerse investigar y acumular todas las pruebas de la existencia de Dios que habían sido formuladas por los filósofos y que como quiera se pudieran formular, convencido como estaba de que todo proceso argumentativo trae nuevos elementos al discurso sobre el Ser absoluto. ${ }^{70}$

Rosmini excluye categóricamente que el hombre tenga una intuición directa de Dios. El ente que nosotros intuimos naturalmente es ilimitado porque "es la esencia misma del ente, pero no es el ente absoluto, porque la intuición no apresa la esencia del ente sino bajo una de sus formas, la forma ideal [...]. En consecuencia, el ente en su totalidad y plenitud no es dado naturalmente a la experiencia del hombre, el hombre no puede saber cómo sea él aunque puede saberlo de una manera trabajosa la inteligencia humana". ${ }^{71}$

Rosmini no niega el valor de las cinco vías de santo Tomás, pero piensa que en el fondo los argumentos a posteriori se fundan sobre un principio a priori, puesto que dichos argumentos tienen valor si son válidos los principios, los cuales no pueden derivar de la experiencia; de otra manera ellos, que son la condición de la cognocibilidad, derivan de lo condicionado, y no tendrían más que un valor subjetivo. Las demostraciones a posteriori tienen, entonces, su base en un principio de razón evidente en sí mismo. De hecho, sobre este punto no existe ningún desacuerdo con santo Tomás, el cual obviamente reconoce el valor absoluto y, por ende, a priori de los principios sobre los que funda las cinco vías. Pero no por esto sus guías se vuelven a priori: porque el punto de partida no es un principio, sino un hecho, un fenómeno susceptible de experiencia sensible.

${ }^{69}$ Cf. F. Percivale 1977.

${ }^{70} \mathrm{Cf}$. Teologia giovanile.

${ }^{71}$ Teodicea, n. 73. 
Entre las tantas vías elaboradas por Rosmini, las más conocidas son las que él propone en el Sistema filosófico, que son cuatro. La primera parte de la esencia del ente intuido, que es eterna y necesaria; la segunda de la forma ideal, que a su vez es un objeto eterno; la tercera de la forma real, en cuanto contigente; la cuarta de la forma moral que es ley eterna, necesaria, absoluta. Leamos juntas estas cuatro argumentaciones:

La primera es por la esencia del ente que se intuye; demostrando que ella no es la nada, sino que es eterna y necesaria. Ahora bien, no podría ser tal si ella no subsistiese idéntica también bajo la forma de realidad y moralidad. Pero la esencia del ente es infinita; y lo que existe bajo las tres formas es el ser infinito en cada una de sus partes; es lo absoluto, es Dios.

La segunda demostración de la existencia de Dios se toma de la forma ideal. Esta forma ideal es luz que crea la inteligencia, y es luz eterna y objeto eterno. Por lo tanto, debe haber una mente [eterna], un sujeto eterno.[...] Este ser absoluto es, por lo tanto, Dios.

La tercera demostración se toma del ser real percibido por el hombre, y es la que hemos mencionado, con la cual la mente va de lo contingente a lo necesario, a la primera causa y razón de todo.

La cuarta demostración se deduce de la forma moral conocida por el hombre. Infinita e insuperable es la autoridad de la ley moral; infinito el valor de la virtud y la pobreza del vicio. Esta fuerza obligante, esta dignidad del bien moral, no es la nada, por lo tanto es eterna, necesaria, absoluta. Pero nada sería si ella no existiese en un ser absoluto. La esencia de la santidad pertenece a la esencia del ser, del cual es el último cumplimiento; de igual manera, a la esencia del ser pertenecen las otras dos formas. Por lo tanto, hay un ser absoluto o Dios. ${ }^{72}$

Las cuatro vías rosminianas están basadas todas en la dignidad, el valor, la eminencia del ser en todas su manfestaciones o formas, ideal, real, moral, una dignidad que lo pone por encima del pensar y del actuar humano, del cual el ser en sí es el criterio, la medida, la forma. Por ello el ser que nosotros intuimos no es un ser puramente relativo a la mente intuyente, sino que antes que nada y necesariamente es un ser en sí, un ser subsistente, Dios.

He aquí otro texto, uno de lo más bellos, en el que argumenta Rosmini la subsistencia del ser a partir de la intuición del ser ideal de parte de nuestra mente:

el ser en universal, pensado por naturaleza por la mente humana, es de tal naturaleza, hemos dicho, que por una parte no muestra alguna subsistencia fuera de la

${ }^{72}$ Sistema filosófico, nn. 178-181. 
mente, y por ende se puede denominar ser lógico; y por otra parte repugna que sea una modificación de nuestro espíritu; es más, explica tal autoridad, a la que nuestro espíritu está totalmente subornidado: nosotros somos conscientes de nosotros mismos de que nada podemos contra el ser, de que no podemos inmutarlo mínimamente; además, es absolutamente inmutable, es el acto cognocible de todas las cosas, la fuente de todas las cogniciones; no tiene nada que sea contigente, como nosotros. Es una luz que percibimos naturalemnte, pero que nos señorea, nos vence, nos enoblece al someternos completamente a sí. Además, podríamos pensar que no existiéramos; sería imposible que el ser en universal, esto es, la posibilidad, la verdad no existiera. Delante de mí lo verdadero es verdadero, no pudo nunca ser en un tiempo diverso a como es. ¿Es esto nada? No, ciertamente, porque la nada no me obliga, no me fuerza a pronunciar nada, pero la naturaleza de la verdad que resplandece en mí me obliga a decir: esto es, y si yo no quisiera decirlo, sabría, sin embargo, que la cosa sería igualmente, aunque yo no quiera. En consecuencia, la verdad, el ser, la posibilidad se me presenta como una naturaleza eterna necesaria, de tal manera que no puede haber una potencia que sirva para deshacer la verdad [...]. Entonces, este hecho de la verdad, que me está presente y es mi luz intelectual, me dice: 1) que hay un efecto en mí que no puede ser producido ni por mí mismo ni por una causa finita; 2) que este efecto es la intuición de un objeto presente a mí, que es intrínsecamente necesario, inmutable, independiente de mi mente y de toda mente finita. Estos dos elementos me conducen por dos vías a conocer la existencia de Dios. ${ }^{73}$

En breve, la trascendencia del ser (y de la verdad) respecto al hombre testifica claramente que su fundamento se encuentra en otra parte: en el ser subsistente, necesario, absoluto, eterno, Dios.

El argumento rosminiano es, igualmente, una paráfrasis, del célebre argumento agustiniano basado sobre la verdad, que siendo superior a nosotros, no puede tener origen más que en Dios mismo con el cual se identifica.

El argumento de Rosmini, como el mismo argumento de Agustín, no puede ser clasificado entre otros argumentos ontológicos (de Anselmo, Descartes, Spinoza, Leibniz). En efecto, no está construido sobre la definición de Dios (lo máximo, aquello de lo cual no se puede pensar nada más grande, lo perfecto), sino sobre un fenómeno, la manifestación del ser (de la verdad) a nuestra mente, una manifestación que exige una razón, una causa adecuada. Por este motivo, Rosmini se pliega abiertamente al principio de causalidad. "Existe una causa que manifiesta una virtud infinita y que por ello debe ser infinita". ${ }^{74}$

\footnotetext{
${ }^{73}$ Nuovo saggio, III, Roma 1934, pp. 268-269.

${ }^{74}$ Ibid.
} 
No obstante esto, Rosmini pretende que la existencia de Dios se argumente $a$ priori incluso si no es per se nota:

Dios existe se debe decir demostrable a priori, pero no per se nota, porque necesita otra proposición precedente en nuestra mente, de la cual y con la cual se argumente; aunque no tiene necesidad de ser deducida a posteriori por las noticias recibidas de los sentidos externos. ${ }^{75}$

La razón por la cual el roveretano sostiene que se puede considerar su demostración a priori y no a posteriori es que la idea del ser de la que parte el argumento no se extrae de la experiencia sensitiva, sino que es fruto de una intuición inmediata y originaria de nuestra mente.

Además del argumento fundado sobre la idea del ser que para Rosmini es el principal, el roveretano presenta a veces otro argumento original, que está perfectamente en línea con su psicología, donde, como se ha visto, además de la idea de ser, hay también otro concepto importante, el "sentimiento fundamental" del propio existir. Sobre este concepto Rosmini basa lo que él llama la prueba del sentimiento. ¿En qué consiste la prueba? En la concatenación necesaria del sentimiento de nuestro existir, que no podemos no advertir más que como limitado y contingente, con el existir de aquel que, poseyendo al ser plenamente e identificándose con el ser mismo, da cuenta de nuestro existir. Gracias a tal sentimiento "la existencia de Dios se vuelve para todo hombre la más fácil y luminosa verdad".

Mientras la primera vía es de tipo "ontológica" y a priori, la segunda, fundada sobre el sentimiento, es claramente de tipo antropológico y a posteriori. De cualquier modo, sea a través de la idea del ser o del sentimiento del propio existir, no hay duda de que para Rosmini el hombre puede darse cuenta fácilmente (racionalmente) de la existencia de Dios.

De un género distinto es el conocimiento que el hombre tiene sobre la naturaleza de Dios. Sobre este punto Rosmini comparte la posición de la teología negativa de Agustín y el pseudo-Dionisio. En el Sistema filosófico el roveretano escribe: "de este Ser absoluto que no intuimos, que no percibimos, nada podemos saber más allá de cuanto nos muestra la misma exigencia de la cognición que podemos tener de Dios en el orden natural, y por ello la cognición nuestra de la divina naturaleza se podría llamar negativa-ideal". La misma tesis es retomada en la Teosofía donde leemos:

${ }^{75}$ Teosofia I, Roma 1938, p. 217. 
en relación a la mente humana, ésta en la presente vida no intuye al Ser absoluto, pero se forma de él un concepto por vía de determinaciones lógicas, concepto verdadero pero negativo. Con este concepto, entonces, se puede definir al Ser absoluto de modo que no se cofunda con ningún otro. Y puesto que aquello que se expresa en la definición de la cosa es la esencia [...] por ello el hombre conoce en cierto grado la esencia de Dios. Pero esta esencia es puramente lógica y negativa; sin embargo, no es falsa, porque aquello que tiene de limitado y defectuoso no puede engañar, porque el hombre reconoce dicho defecto. ${ }^{76}$

Una acusación de la que Rosmini siempre se ha defendido es la del ontologismo. Según sus adversarios, si se atribuye al hombre, como hace el roveretano, una intuición del ser ideal, es necesario admitir que el hombre conoce directamente a Dios. Desde 1830, en el Nuovo saggio sull'origine delle idee, Rosmini precisa cómo se debe negar que el ser dado inmediatamente a la mente pueda identificarse con Dios: "si este se desplegase de modo más manifiesto frente a nuestra mente, haciendo brotar del propio fondo la actividad propia, y con ello se terminase y cumpliese, veríamos a Dios. Pero, lejos de ello, no vemos naturalmente al ser sino en modo imperfecto, y su actividad inicial nos esconde su término". ${ }^{77}$, n. 1179.

Entre el ser ideal y determinado y el ser real infinito no existe ningún paso inmediato. Se necesita del puente del ser real finito y éste es sólo un símbolo y no un espejo del ser real infinito. Escribe Rosmini en su Teosofía:

(el ser ideal) contiene al real virtualmente en las propias vísceras, y esto basta para hacer que él se pueda comunicar y para dar indicio de la necesidad de lo real correspondiente; pero no basta para hacer que se perciba actualmente al real mismo.

Contener en las propias vísceras virtualmente lo real y tener en sí la razón de esto, es lo mismo. Por ende, es que se tiene en lo solo real un punto en el cual la mente apoyándose se puede lanzar a adivinar, por decir así, que un real correspondiente al ideal deba existir, aunque no lo perciba, ni sepa determinar sus cualidades positivas. Pero la mente por ello no puede elevarse a tal inducción si antes no ha sido puesta en movimiento y si no ha conocido por experiencia a algún real finito. En consecuencia, hay en el ideal una ciencia tal de simple indicación [...] de lo real: ciencia que nosotros llamamos negativa, porque no sabe indicar las cualidades positivas de lo real, de las que, sin embargo, la necesaria existencia divina reclama $[\ldots]$.

Por tanto, debe concluirse que el ser real infinito no puede ser percibido por ningún ente finito por su propia naturaleza, sino que sólo el infinito real se puede percibir

${ }^{76}$ Ibid. V, 1939, p. 88.

${ }^{77}$ Nuovo saggio 
a sí mismo por su naturaleza. Por ello, si el ser finito percibe lo real infinito, no puede percibirlo más que como cosa extraña a su naturaleza y por ende como cosa agregada y dada de otro lado. Y esto es lo que enseñan también los teólogos cristianos cuando dicen que ningún ser finito puede ver a Dios por naturaleza sino solo por gracia. ${ }^{78}$

Por tanto, excluido que el objeto de la intuición natural sea Dios, Rosmini pasa a ver cuáles pueden ser las cogniciones que nosotros nos proveemos naturalmente sobre este Ser superior a la naturaleza. Para resolver este problema, la mayor parte de los escolásticos habían apelado al principio de la analogía. Es lo que hace también Rosmini.

Para lo que se refiere al conocimiento de Dios, el roveretano distingue tres fuentes: la revelación, la creación y el "razonamiento ontológico". Según Rosmini, la "vía tortuosa" de la analogía comprende dos momentos, uno positivo y otro negativo. En el primero se "razona sobre Dios con las ideas imperfectas y analógicas extraídas de las naturalezas contingentes, las únicas que tenemos". En el segundo "se reconoce que este discurso nuestro es imperfecto, limitado, inadecuado, sin poderlo cambiar en otro perfecto, ilimitado, adecuado al gran argumento". ${ }^{79}$ Para sostener su interpretación de la doctrina de la analogía — que es una interpretación reductiva respecto a la doctrina dionisiana y tomista, que al momento positivo y negativo agregan un tercer momento, el eminencial—, Rosmini analiza ideas como sabiduría, bondad, potencia, etcétera, y alcanza los siguientes resultados:

No teniendo nosotros a disposición otro medio para conocer que el uso de tales ideas, estamos obligados a intentar conocer con ellas también a Dios, y en parte lo venimos a conocer verdaderamente, porque agrega al razonamiento ontológico, el cual nos dice que cada una de dichas perfecciones que están separadas fuera de Dios, en Dios son Dios mismo [... ]. Pero el razonamiento nos dice que así debe ser respecto al Ser supremo, no nos explica sin embargo cómo sea, es decir, no nos muestra ninguna perfección subsistente; por lo que nos dice lo que Dios no es, no lo que Dios es: una subsistencia, que en su simplicidad encierra aquello que tiene la especie y el género; no nos muestra, no nos hace percibir, pensar una subsistencia tal, más de lo que la definición de color hace pensar al ciego; nos muestra los términos, pero no su nexo, en el cual consiste el ser divino. ${ }^{80}$

\footnotetext{
${ }^{78}$ Teosofia V, Roma 1939, p. 379.

${ }^{79}$ Psicologia III, Milán 1949, pp. 23ss.

${ }^{80}$ Ibid., pp. 25-26.
} 
Aunque el conocimiento que tiene el hombre sobre Dios sea extremadamente pobre, limitado y substancialmente negativo, sabe que comoquiera Dios no puede estar privado de aquellas potencias espirituales de las que él mismo está dotado, el intelecto y la voluntad y de una larga de perfecciones como la sabiduría, la bondad, la belleza, el ser mismo, la simplicidad, la eternidad, la infinitud, etcétera.

De todas las operaciones divinas, en cualquier sistema metafísico, la que cuenta mayormente es la creación. Esta operación es el resultado del amor de Dios ad extra hacia las criaturas, un amor que presupone un acto de la divina sabiduría, que predispone un ejemplar del mundo que busca crear. He aquí cómo Rosmini describe los dos momentos, de la concepción y la realización de la creación:

Hemos dicho que la creación es la obra de la libertad creadora de Dios. La libertad creadora es una virtud, un poder del Ser absoluto en su forma subjetiva. El Ser absoluto en su forma subjetiva se ama infinitamente a sí mismo entendido en su forma objetiva: el Ser ama infinitamente al Ser. Este amor lo lleva a amar al ser en todos los modos en que es amable, en los cuales puede ser amado. Para amarlo en todos los modos lo ama no sólo como Ser absoluto e infinito, sino también como ser relativo y finito: este amor es el acto creativo. Crea, entonces, por sí mismo un objeto finito amable, por la expansión del amor, y esto es el Mundo. Para crearlo debe: $1^{\circ}$ concebirlo, puesto que este principio creativo es inteligencia y porque no se puede amar lo que no se entiende; $2^{\circ}$ realizarlo, porque si no fuese realmente en sí el objeto del amor, no existiría, sino que solo sería posible, y aquello que se ama visto en su posibilidad se quiere que exista. En consecuencia, los dos elementos de la esencia y de lo real nacidos en un solo parto, forman los entes mundanos. ${ }^{81}$

En el primer momento Dios ve en sí mismo ab aeterno al ser finito, todo virtualmente en él comprimido. Esta visión del ser finito en lo infinito no es todavía el acto libre de la creación, sino pertenece al acto necesario de la divina inteligencia con el que conoce al ser finito posible: es el acto con el que la Mente divina concibe al ejemplar del mundo, o sea, al complejo de las esencias de las cosas finitas. Sucesivamente la libertad divina, "guiada por la amabilidad del ser limitado", procede a la creación del mundo.

\section{Relaciones entre el hombre y Dios}

Las relaciones que se dan entre el hombre y Dios son de tres géneros: ontológicas, éticas, religiosas.

\footnotetext{
${ }^{81}$ Teosofia II, ed. cit., n. 460.
} 
Al grupo de las relaciones ontológicas pertenecen las grandísimas expresiones del amor divino que se llaman creación, conservación, providencia y redención. Para todo hombre, que es un subsistente en el orden del espíritu, Dios nutre un amor personal. Como se ha visto, Rosmini subraya el aspecto agápico ya en el acto creativo pero lo evidencia en todas las otras relaciones que Dios tiene con el hombre.

$\mathrm{El}$ hombre tiene relaciones éticas ya consigo mismo y con el prójimo, pero la relación ética más importante es la que tiene con Dios. Norma fundamental de moral rosminiana es el reconocimiento del ser. Ahora bien, tal reconocimiento es máximamente exigente en el caso de Dios, que es el Ser subsistente mismo. El hombre, además de reconocimiento, le debe obediencia. Efectuando la voluntad de Dios, el hombre progresa hacia la plena realización del propio ser.

Todavía más íntimamente el hombre se une a Dios mediante las relaciones religiosas. Se expresan en el culto, en la plegaria, en la adoración, en el sacrificio.

La religión es un deber de justicia que la criatura tiene hacia su creador, que adquiere un carácter todavía más noble cuando es corroborada por las virtudes cristianas de la fe, esperanza y caridad. Gracias a estas virtudes, el hombre es transformado en su interior ontológicamente y es introducido en un nuevo mundo, el mundo sobrenatural. La religión misma pasa del orden natural al orden sobrenatural. Como explica Rosmini en la Antropologia soprannaturale, el elemento que especifica a una religión sobrenatural respecto a todas las religiones naturales consiste en una "acción real que Dios mismo obra en el espíritu del hombre", llevando al "espíritu humano a una íntima y real unión con la divinidad". Esta acción divina real, que el hombre recibe en la esencia del alma, donde ella produce un principio activo nuevo "supremo, muy noble, potentísimo", es la gracia. El primer acto de la gracia es la fe, la cual, según Rosmini, resulta compuesta de la concepción divina incipiente y del asentimiento de la voluntad humana. La gracia tiene un modo de obrar deiforme, esto es, "no sólo tiene por principio a Dios, sino que ella misma y su término es Dios". Dios, entonces, obra en el alma humana como causa formal objetiva; es decir, "es forma objetiva del espíritu elevado al estado de gracia no ya con su modo ideal [...] sino consigo mismo inmediatamente, con su propia substancia". 82

${ }^{82}$ Antropologia soprannaturale, Roma 1983, p. 131. 
Aquí no nos es posible seguir a Rosmini en su docto e interesantísimo análisis de la vida del alma elevada al orden sobrenatural. Nos basta con leer la página en la que él resume esta parte de la Antropologia soprannaturale:

El ser en el hombre naturalmente se encuentra en un estado muy imperfecto, esto es, el hombre, mientras no sobrepase el orden de la naturaleza, no ve al ser más que imperfecta, inicialmente, en un modo universal, indeterminado, sin una subsistencia en sí y por ello como posible. Este ser posible e indeterminado que el hombre ve por naturaleza y que aplica luego a los sentimientos le hemos llamado ser ideal o bien modo ideal del ser.

El ser en el hombre toma un nuevo estado una vez que es elevado del orden natural al orden sobrenatural: este ser obra en el hombre ya no de un modo puramente ideal, sino de un modo substancial y real; el hombre experimenta entonces un verdadero sentimiento, ya no una tenue idea; experimenta la acción del ser real que se manifiesta de tal modo presente a él, ya no sólo la posibilidad indeterminada del ser que tiene en sí, sino la subsistencia misma. En suma, la idea se cambia en perfección. El ser real que percibe el hombre en tal estado no es por ello limitado, sino más bien está determinado por la propia subsistencia, no es posible sino universal en cuanto el todo se encuentra en él; no es inicial sino más bien completo. Este ser completo y real es Dios mismo, el cual en este mundo no se muestra sino de modo velado; y sólo en el otro se ve desveladamente y con plenitud. ${ }^{83}$

Con la práctica de las virtudes sobrenaturales de la fe, la esperanza y la caridad, el hombre se une siempre más íntimamente a Dios y se acerca a la felicidad eterna donde todo es Amor. He aquí cómo Rosmini describe en una página lírica el asunto de la beatitud eterna:

De donde se ve qué rueda de perpetuo movimiento luminoso y gozoso gira en las almas beatas de aquellos santos que tienen en sí mismos la Trinidad. Porque el Amor siempre está en actividad dentro de ellos para contemplar la Sabiduría, en la cual se ve su principio como infinito y necesario, a cuya vista el alma se une más y es atraída a la sabiduría subsistente que emana de sí un Amor infinito, el cual regresa a reflexionarse en aquella sabiduría que es luz que muestra el eterno primordial principio altísimo, el cual obrando perpetúa este asunto deleitadísimo y casi ondulante de recóndito y secretísimo gozo. Por lo que la fe negativa de la Trinidad que se tiene por la revelación externa no tiene todavía la inmensa acción interior y el positivo sentimiento de las personas, pero, entonces, cuando el Espíritu da principio al obrar, da la eficacia a aquellas ideas negativas que ya eran en ella, por la revelación externa, un todo verdaderamente positivo se persigue, donde

${ }^{83}$ Ibid., p. 278. 
comienza ya aquella perpetua acción y dirección circular de las formas "trinas", que es una cierta participación inefable de la vida de Dios. ${ }^{84}$

Así, el círculo de la aventura humana que viene a través del exitus y el reditus se consuma al final, gracias a la acción redentora del Cristo, en el círculo agápico infinitamente gratificante de la Santísima Trinidad.

\section{Conclusión}

Verdad y amor: sobre este binomio específicamente cristiano, Antonio Rosmini ha efectuado una profunda renovación de la filosofía cristiana en diálogo con la cultura moderna.

Sin embargo, en sus tiempos su labor no fue apreciada ni dentro ni fuera de la Iglesia. La suya fue la voz de "quien clama en el desierto". De hecho, precisamente en el momento en el que Rosmini cumplía su tentativo valiente, la cultura moderna, bajo las durísimas críticas de Marx y Nietzsche, se estaba rápidamente desarticulando y disolviendo.

No puede, por ello, constituir una sorpresa si la nueva filosofía cristiana de Rosmini no tuvo una acogida favorable de parte de un mundo laico siempre más secularizado y dirigido hacia una firme descristianización.

Lo que sorprende, y lo que a veces llama la atención de los historiadores, es la hostilidad con la que Rosmini fue acogido en los ambientes católicos. En sus confrontaciones se delineó bien pronto una acentuada oposición, y se desarrolló así la denominada "cuestión rosminiana". Sus primeras obras fueron recibidas con simpatía en los ambientes eclesiásticos: Gregorio XVI, aprobando el Instituto de la Caridad (1839), presentaba a Rosmini, entre otras cosas, como hombre "rerum divinarum atque humanarum scientia summopere illustrem". Pero su crítica al probabilismo moral (en el Trattado della coscienza), el aire de novedad y ciertas posturas políticas demasiado "liberales", parecían una ofensa a la tradición. La primera fase polémica entre los secuaces y adversarios de Rosmini, en el campo eclesiástico, se tuvo en los años 1840-43, y terminó con un decreto de Gregorio XVI que imponía silencio a todos los contendientes. Pero fue retomada en 1849, tomando inspiración de los asuntos políticos y la condena del Índice de dos obras rosminianas: Delle cinque piaghe della Santa Chiesa y Costituzione secondo la giustizia sociale. En 1851 Pío IX convocó consigo la cuestión entera, y luego de un cuidadoso

${ }^{84}$ Ibid., p. 226. 
examen de tosas sus obras, en 1854 las admitió para que fueran leídas por los fieles con la fórmula Dimittantur, prohibiendo repetir las viejas acusaciones a Rosmini y de alegar nuevas. Sin embargo, la polémica se volvió a encender durante el pontificado de León XIII, luego de la publicación de algunas obras póstumas, y así, en 1888, veía la luz un nuevo decreto de la Congregación del S. Oficio, Post obitum, en la que 40 proposiciones, 29 extraídas de sus obras póstumas y 11 de las anteriores, eran señaladas porque "catholicae veritati haud consonae videbantur", y así eran prohibidas. ${ }^{85}$

Sobre el valor y significado de aquel decreto se ha discutido mucho, con interpretaciones rígidas y restrictivas de parte de los adversarios de Rosmini, y con interpretaciones más abiertas e indulgentes de parte de sus defensores. Las investigaciones más recientes parecen justificar la tesis de aquellos que afirman que también aquellas proposiciones que podían parecer incluso heterodoxas, se pueden interpretar con un significado plenamente ortodoxo. ${ }^{86}$

Para nosotros aquí la "cuestión rosminiana" cuenta muy poco. En una historia de la metafísica, como la que reconstruimos, las cosas que interesan, en definitiva, son sólo dos: 1) el puesto que ocupa Rosmini en esta fascinante historia, 2) la relación de la metafísica de Rosmini con la de Tomás de Aquino.

En relación al primer punto, no hay duda de que el puesto que ocupa Rosmini es muy importante. Sobre todo porque Rosmini es el único gran metafísico del siglo XIX, el único que tuvo el coraje, después de Kant, de afrontar nuevamente el problema del ser. En segundo lugar, porque ha logrado hacerlo de modo original, elaborando una ontología triádica, que presenta al ser bajo una triple forma (ideal, real, moral) y asignando la misma dignidad a cada una.

Lo que caracteriza a una metafísica es siempre el principio primero que funge como base de todo el edificio. El filósofo roveretano no construye su edificio sobre el Uno o el Bien, o lo Verdadero o lo Infinito, o sobre la Substancia, sino directamente sobre el ser, así como habían hecho Parménides, Aristóteles y Tomás de Aquino. Pero mientras sus ilustres predecesores habían construido todo el edificio sobre la forma real del ser, Rosmini renueva el edificio metafísico poniendo como fundamento al ser trino, o sea, las tres formas primarias del ser. De este modo, el roveretano da a su "enciclopedia filosófica" una profunda unidad, incorporando prácticamente la ideología en la metafísi-

${ }^{85}$ Cf. el DTC III, col. 2929ss., que tiene el texto completo de las proposiciones prohibidas.

${ }^{86}$ Cf. C. Fabro, L'enigma Rosmini, Nápoles 1988. 
ca y haciendo de la moral un apéndice necesario de la metafísica. En efecto, el ser no puede no ser conocido (ideología) y no puede no ser amado (moral).

Más que por su ideología y su moral, Rosmini es grande y original por su metafísica. Es el punto más fuerte y robusto de todo su pensamiento, y no la ideología, como a menudo se cree. Diría, es más, que la ideología es su punto más débil y menos original.

La ideología rosminiana es claramente de estampa agustiniana y buenaventuriana, los dos grandes pilares de la doctrina de la iluminación que, por tanto, podía gozar de una prestigiosa y noble paternidad que la vuelve digna de respeto también a los ojos de la filosofía tomista.

Ahora bien, mientras que es indudablemente válida la tesis que afirma que la idea del ser es la idea primigenia, primordial, la primera que se asoma a la inteligencia humana, tanto que en un cierto sentido se puede decir que ella enciende la luz de nuestra inteligencia, permanece, por el contrario, dudosa la explicación (de Agustín, Buenaventura y Rosmini) que quiere que ésta sea una idea innata, fruto de una iluminación externa de nuestra mente, la cual, de frente a tal idea, se comportaría de modo totalmente pasivo. Esta explicación, que niega la actividad del intelecto precisamente en el momento en que inicia el conocimiento intelectivo, mientras procura al intelecto un más seguro acceso al conocimiento de la verdad, efectúa una grave detracción en las confrontaciones de su grandeza y su autonomía. Rosmini abrazó esta solución porque quería secundar a Kant en la tesis de la aprioridad de algunas ideas (categorías) fundamentales, pero al mismo tiempo quería liberar esta tesis de la hipoteca del subjetivismo kantiano. Y, así, la teoría de la iluminación le parece una óptima solución. Pero, repito, no está aquí ni la grandeza ni la originalidad de Rosmini.

En relación al segundo punto, a saber, las relaciones entre Rosmini y santo Tomás, hay un fuerte contraste entre los estudiosos. Rosmini conocía bastante bien a santo Tomás y lo cita muy a menudo. Pero una de las razones de la condena del roveretano está en un contraste, a primera vista bastante claro, entre sus posiciones y las de Doctor Angélico.

Un camino, que ha sido recorrido habitualmente, por los secuaces y defensores de Rosmini, para probar la ortodoxia de su pensamiento, ha sido la de ponerlo a confrontación con el pensamiento de santo Tomás y mostrar "un substancial acuerdo de santo Tomás con Rosmini” (G. Muzio).

Este camino puede parecer inteligente y fructuoso, pero a mi parecer es errado y, todo sumado, contraproducente. 
La tentativa de salvar a Rosmini buscando sus puntos de contacto con santo Tomás es sumamente comprensible, porque santo Tomás es el doctor communis, reconocido oficialmente por la Iglesia como tal e indicado siempre como ejemplo para todos los pensadores católicos, en cuanto ha llegado a dar de toda verdad una explicación racional convincente y plausible. Así, les ha parecido lógico a los secuaces de Agustín, Buenaventura, Escoto y Rosmini buscar mostrar que el pensamiento de estos excelentes pensadores cristianos coincide substancialmente con el de santo Tomás.

Ahora bien, es muy cierto esto en lo que se refiere a la teología. Son todos teólogos ortodoxos y maestros insignes de la ortodoxia católica. Pero no se puede decir lo mismo de la filosofía, la cual, como sabemos, es una libre especulación de la razón humana en torno a la realidad y verdad y una investigación de una solución racional a los mayores problemas que atosigan a la inteligencia humana. Mientras la teología trabaja sobre verdades ya dadas por la revelación (sus principios son los misterios revelados), la filosofía va la búsqueda de la verdad, como algo ignoto y difícilmente alcanzable.

Sin embargo, también en lo que atañe a las conclusiones de la investigación metafísica (en torno al alma, a Dios y al mundo) hay un substancial acuerdo entre Agustín, Tomás, Buenaventura, Escoto y Rosmini. Pero reivindicar, como han hecho y continúan haciendo muchos rosminianos, un substancial acuerdo entre Tomás y Rosmini es errado.

Es errado porque no es posible hacer coincidir ni la ideología ni la ontología de Rosmini con la ideología y la ontología del Aquinate. No es posible hacer coincidir sus gnoseologías. Indudablemente ambas son realistas y no subjetivistas, pues afirman que la verdad es medida de nuestro conocimiento y no el conocimiento metro de la verdad. Pero el de santo Tomás es un realismo moderado de estampa aristotélica, mientras que el de Rosmini es un ultrarealismo de estampa platónica. Tanto menos es posible hacer coincidir la metafísica rosminiana con la tomista. Hay, sobre todo, una profunda diversidad de método. El de Rosmini va de lo alto a lo bajo y es circular, y por ello se concluye con una circunnavegación del gran mar del ser. El del Angélico va de lo bajo a lo alto, de los entes al esse ipsum subsistens y lo que realiza es la segunda navegación.

Pero entre las dos metafísicas hay también una diferencia de fondo, que es una diferencia substancial y no de hecho secundaria. En efecto, en la metafísica rosminiana están ausentes dos doctrinas capitales de la metafísica tomista: la doctrina de la distinción real entre la esencia y el actus essendi (una distin- 
ción que Rosmini no ignora, pero a la cual de hecho no da ninguna importancia), y la doctrina del acto y la potencia. Estas dos doctrinas atraviesan todo el edificio metafísico tomista y consienten al Doctor Angélico el elaborar una metafísica "existencialista", como ha sido dicho por Gilson y Maritain, y una metafísica fuertemente ontológica en sentido realista. Rosmini trabaja más bien con la pareja posibilidad-necesidad y extrae la necesidad de la posibilidad, como había hecho Leibniz. En consecuencia, el argumentar rosminiano asume un andamiaje ontologístico y la metafísica del roveretano se vuelve necesariamente una metafísica de los existentes. El ser, en vez de actus essen$d i$, es concebido por Rosmini como una esencia universal que contiene todas las esencias posibles particulares; y como escribe el propio Rosmini, "todo el orden del ser se extrae del ser como el hilo del capullo".

Lo que es cierto es que también la metafísica de Rosmini es, como la de santo Tomás, una metafísica cristiana y una metafísica del ser. Pero reducir la metafísica de Rosmini a la del Angélico es una operación contraproducente, y no trae ninguna ventaja al nombre del roveretano.

Como ha mostrado E. Gilson en su magistral Historia de la filosofía medieval, en el cristianismo hay lugar para muchas metafísicas, y también para muchas metafísicas del ser, porque, a nivel reflejo, del ser es posible elaborar varios conceptos, y asumir cualquier concepto como fundamento del edificio metafísico. Todas las metafísicas del ser construidas sobre la base del canon de la substancial armonía entre fe y razón, como han hecho Tomás, Buenaventura, Escoto y Rosmini, son perfectamente legítimas, también si, ante la indagación crítica, su valor puede resultar desigual. Pero todo edificio metafísico merece ser estudiado y apreciado por sí mismo, evitando hacer de los edificios más recientes reconstrucciones de los más antiguos. La clonación metafísica es igualmente ilícita como la clonación humana.

Rosmini tiene un concepto muy elevado del ser. Algunas de sus expresiones lo acercan al concepto intensivo de santo Tomás. También para el roveretano, el ser es la perfección máxima, la perfección de todas las perfecciones, la actividad de todas las actividades. Y, sin embargo, no construye su metafísica sobre el actus essendi sino sobre la idea del ser. Y esto vuelve substancialmente diversa su metafísica de la de santo Tomás.

\section{Sugerencias bibliográficas}

\section{Ediciones}


1934-77, Edizione nazionale delle opere edite e inedite, al cuidado de E. Castelli, 49 voll., Bocca Milán (voll. I-XI); Anonima Romana Editrice, Roma (voll. XIIXXVIII); Cedam, (voll. XXIVss), Padua.

Opere edite e inedite, 80 voll., edición crítica promovida por M. F. Sciacca, al cuidado del Centro Internacional de Estudios Rosminianos y Città Nuova, Stresa-Roma, 1975ss.

1887-94, Epistolario completo, 13 voll., Edizioni Rosminiane Sodalitas, Stresa.

1967, Teosofia, al cuidado de M. L. Raschini, 2 voll., Marzoratti, Milán.

Estudios

Antonelli, M. T., (1957), Studi rosminiani, Sodalitas, Domodossola 1955. Atti del congresso internazionale di filosofia Antonio Rosmini, al cuidado de M. F. Sciacca, Le Monnier, Florencia.

Berti, E., (1978), La metafisica di Platone e di Aristotele nella interpretazione di Antonio Rosmini, Centro Internazionale di Studi Rosminiani, Stresa-Roma.

Brunello, B., (1963), Rosmini. Dal sistema all'etica e al pensiero politico, Patron, Boloña.

Bulgeretti, L., (1942), Antonio Rosmini nella Restaurazione, Le Monnier, Florencia.

Capone B. G., (1914), Saggio su Rosmini. Il mondo delle idee, Librería Editrice Milanese, Milán.

Fabro, C., (1988), L'enigma Rosmini, Nápoles.

Gentile, G., (1960), Rosmini e Gioberti, Pisa 1898; 3a. ed., Sansoni Florencia.

Giacon, C., (1960), L'oggettività di Antonio Rosmini, Silva, Milán-Génova.

Gonella, G., (1934), La filosofia del diritto secondo A. Rosmini, Studium, Roma.

Leetham, C., (1957), Rosmini, Longmans-Green, Londres-Nueva York.

Mancini, I., (1963), Il giovane Rosmini, I, La metafisica inedita, Argalla, Urbino.

Manferdini, T., (1994), Essere e verità in Rosmini, ESD, Boloña.

Menke, K. H., (1980), Vernunft und Offenbarung bei Antonio Rosmini. Der apologetische Plan einer christlichen Enzyklopädie, Tyrolia Verlag, Innsbruck-VienaMúnich.

Ottonello, P. P., (1967), L'essere iniziale nell'ontologia di Rosmini, Marzoratti, Milán. Id., (1992), L'enciclopedia di Rosmini, L'Aquila-Roma.

Piovani, P., (1957), La teodicea sociale di Rosmini, Cedam, Padua.

Prini, P., (1961), Introduzione alla metafisica di Antonio Rosmini, Sodalitas, Domodossola 1953(luego en Rosmini postumo. La conclusione della filosofia dell'essere, Armando, Roma).

Raschini, M. A., (1985), Studi sulla teosofia rosminiana, 2a. ed., Génova.

Id., (1996), Dialettica e poiesi nel pensiero di Rosmini, Venecia.

Riva, C., (1956), Il problema della origine dell'anima intellettiva in Antonio Rosmini, Sodalitas, Domodossola.

Sancipriano, M., (1968), Il pensiero politico di Haller e Rosmini, Marzoratti, Milán. Schiavone, M., (1962), L'etica di Rosmini e la sua fondazione metafisica, Marzorati, Milán.

Sciacca, M. F., (1961), La filosofia morale di Antonio Rosmini, Marzoratti, Milán. 
Id., (1963), Interpretazioni rosminiane, Marzoratti, Milán 1958 (2a. ed.,). Solari, G., (1957), Studi rosminiani, al cuidado de P. Piovani, Giuffré, Milán. Zolo, D. (1963), Il personalismo rosminiano, Morcelliana, Brescia . 